\title{
LINGÜÍSTICA Y DERECHO
}

\author{
Francisco J. García Marcos \\ Universidad de Almería
}

\section{Resumen}

This paper is an introduction to the relationships between Law and Linguistics, a new interdisciplinary field of scientific research. This interdisciplinarity is primarily analysed in general terms and, secondly, it is also considered in its singular perspectives: sociological Linguistics, Pragmatics, and Phonetics.

\section{Lingǘstica y derecho, una convergencia anunciada e ineludible}

Supongo que cuando los historiadores revisen la lingüística con la que ha concluido el siglo XX podrán acusarla de cualquier cosa menos de rehuir responsabilidades sociales que, tan sólo unas décadas antes, hubieran sido casi impensables. Entre estas, sobre todo durante sus dos últimas décadas, se ha incluido una precavida, aunque firme, atención por el mundo jurídico. Recorriendo ese camino, más o menos a mitad del mismo, los lingüistas han coincidido con quienes desde el extremo opuesto, desde el derecho, compartían idéntico empeño. En realidad, la mutua aproximación de lo lingüístico y lo jurídico, aun estando inserta en el vasto marco de las aplicaciones lingüísticas finiseculares, no deja de contener algo de antiguo y, a la vez, mucho de rutilante novedad. De antiguo porque descansa en una ligazón subrepticia que vincula ambas disciplinas, se diría que de modo poco menos que consustancial. A la vez, su novedad radica en que todavía hoy constituye un ámbito de exploración profunda, de asentamiento disciplinar pleno y reconocido en la comunidad académica. El que existan bibliografias panorámicas sobre esa interrelación lingüístico-jurídica no restaña la sensación, inquietante y sugerente a la vez, de estar todavía transitando por los andamios de la que está llamada a ser una de las grandes aplicaciones de la lingüística. Son, justamente, bibliografías de esa enjundia uno de los principales argumentos que abonan esa presunción de falta de completa delimitación disciplinar a la que estoy aludiendo. Aunque la decana de ellas ronde el cuarto de siglo (Gémar, 1978), y a pesar de haber tenido sus continuadores $^{1}$ en la década siguiente, en 1990 Danet no le concedía más allá de quince años de antigüedad a los estudios sobre lengua y derecho, o lo que viene a ser lo mismo, excluía una parte considerable de los repertorios anteriores. Ante estos y otros hechos similares, quienes más recientemente han trazado panorámicas generales sobre ese campo interdisciplinar no pueden evitar que se le siga asignando un marchamo de relativa indefinición, de carencia de completo asentamiento científico, unívoco y sin ambages.

Hilgendorf (1980), Bülow y Schneider (1981), Levi (1982) y Reitemeier (1985).

ELUA, 18, 2004, págs. 59-86 
Por mi parte, estoy persuadido de que están condenados a alcanzarlo; más aún, de que, como queda dicho, están llamados a convertirse en una de las principales fronteras de aplicación de la lingüística y, quizá, incluso también de las ciencias sociales en su conjunto. Como iremos viendo al adentrarnos en los diferentes apartados que componen este trabajo, la interdisciplinariedad termina surgiendo en prácticamente todas las facetas susceptibles de vincular la lingüística con el mundo del derecho. Desde luego, creo que disponemos de alicientes objetivos más que sobrados para proseguir en esa clase de indagaciones. La práctica jurídica, en sus diferentes aspectos y componentes, ha descansado en destrezas lingüísticas que en alguna medida conciernen a la lingüística, sobre todo a poco que seamos generosos y adoptemos una perspectiva con un mínimo de modernidad acerca de cuáles son los cometidos de nuestra disciplina. Tampoco es cuestión de realizar la consabida apelación a la historia y recordar que, cuando arranca la escritura en la Mesopotamia del III Milenio a. C., el escriba, además de perito en el manejo de esa destreza, es contable y jurista, ni recordar que la escritura nace con la primera y primordial misión de legislar, juzgar y transmitir el resultado de ambas acciones a los confines de aquel imperio. Basta simplemente con percatarnos de que la misma redacción de los documentos que sirven de base a las actuaciones judiciales requieren, para empezar, del dominio perito de una jerga específica, para continuar, de una alta cualificación y un buen adiestramiento de cara a su descodificación $y$, por ultimo, del manejo de información contextual que nos permita comprender la verdad última de los textos jurídicos, saber valorarlos $\mathrm{y}$, si fuera pertinente, someterlos a revisión y a crítica. Ese elemental circuito comunicativo, que se desprende sin mayores dificultades de una simple aproximación a la cotidianidad de ese mundo, ha sido tradicionalmente asumido dentro de la formación específica de los juristas. Una parte nada desdeñable de la práctica judicial se desempeña desde lo que podríamos tildar de hermenéutica jurídica: los abogados y fiscales defienden sus argumentos avalados por lecturas e interpretaciones del corpus legal, confirmadas o refutadas en los fallos de los jueces, quienes, a su vez, para ello proceden a realizar su propia hermeneusis, refrendada en esta ocasión por la posición de autoridad que ostentan. Todo ello requiere de una retórica específica, cuyo desconocimiento o impericia sitúa directamente fuera de la práctica jurídica a quienes las padecen. Los márgenes y canales entre los que se desenvuelve esa retórica oscilan en función de la propia naturaleza de los sistemas judiciales. En el español prima claramente el soporte escrito, y tanto las distintas diligencias como las comparecencias orales que se registran durante el proceso judicial están sujetas a reglas muy estrictas, de una rigidez que se diría rayana en lo incomunicativo o acomunicativo ${ }^{2}$. Sin embargo, en otros sistemas, cuyo prototípico y más difundido exponente sería el norteamericano, la oralidad puede alcanzar un peso determinante, entre otras cosas porque los procesos admiten una destreza argumental mucho más abierta, más personal, directa y creativa. Esa posibilidad, sin duda, mueve a un conocimiento profundo de las artes retóricas en el sentido más clásico del término. Hasta tal punto es así que muchas facultades de derecho estadounidenses la incluyen como materia ordinaria en sus planes de estudio, sugerencia que también está empezando gradualmente a seguirse en otras partes del mundo.

\footnotetext{
2 Me refiero, por ejemplo, al uso de fórmulas fijas e inamovibles, como el "es cierto que..." con el que se inician los interrogatorios que los letrados dirigen a los testigos durantes las vistas orales. Ello complica enormemente el diálogo, incluso la propia formulación clara y sin equívocos de muchas preguntas.
} 
Retomaré con mayor detenimiento algunas de las cuestiones que solo he pretendido bosquejar hasta ahora. De momento permítaseme señalar que los modernos intereses lingüísticos que buscan coincidir con el derecho parten justo de aquí, de esa profusa y diversificada constelación de actos comunicativos que concita, que ha concitado desde siempre, el ejercicio de la justicia en todas sus facetas y en buena parte de las actividades que le están, directa o indirectamente, vinculadas.

No me atrevería a decir tajantemente que durante mucho tiempo los lingüistas hayamos contemplado todos estos hechos con escepticismo manifiesto. Ya he referido que prácticamente hasta el último tercio del siglo pasado, por la evolución de nuestra historia disciplinar, estas y otras aplicaciones de la lingüística simplemente no las veíamos, o casi nos pasaban por completo desapercibidas. Aunque hoy nos resulten familiares, incluso inexcusables en nuestra actual topología disciplinar, lo cierto es que durante siglos para los lingüistas, o para quienes se preocuparon por cosas relacionadas con el lenguaje y las lenguas, como mucho llamaron su atención algunos aspectos de la enseñanza de lenguas a extranjeros, con y sin fines específicos ${ }^{3}$, el adiestramiento lingüístico de sordos (o no normoyentes), los sistemas de comunicación artificiales, y poco más; todas ellas inquietudes puntuales y coyunturales, sin tradición y, por supuesto, sin ubicación dentro de las competencias del estudio propiamente lingüístico. Incluso un siglo como el XIX, tan inquieto e inquietante en múltiples aspectos, tan fundacional para una parte de la lingüística moderna, pero también tan proclive a abrir nuevas vías de diálogo con otras ramas de conocimiento ${ }^{4}$, sin embargo en lo tocante al mundo jurídico parecía algo más que remiso, incluso en lo que más tarde hubiéramos adscrito a la más externalista preocupación lingüística. En la monumental Biblioteca Filológica elaborada en España por el Conde de la Viñaza, las páginas encargadas de consignar la producción lexicográfica de relieve nos aportan muy indicativas noticias al respecto. De los 81 diccionarios y vocabularios comentados, tan solo dos están consignados al derecho, ambos publicados en $1831^{5}$. Antes encontramos referencias al derecho civil y al canónico en el inmenso Diccionario castellano con las voces de ciencias y artes y sus correspondientes en las tres lenguas francesa, latina é italiana (1786-1793), auténtico compendio del saber enciclopédico de su tiempo surgido de la mano de Esteban de Terreros y Pando. Las cuestiones jurídicas son de las últimas que suscitaron el interés de los autores españoles, muy por detrás en lo cronológico de las náuticas, las médicas, las geográficas o, entre otras, las relacionadas con la artesanía.

Durante décadas lo jurídico ha llamado la atención de la lingüística solo como un yacimiento fecundo y accesible de materiales. Bien conservados, por lo general excelentemente catalogados, muy regulares y estables, los textos jurídicos han sido de extraordinaria utilidad para los historiadores de las lenguas. Su evidente carácter arcaizante introducía un cierto

3 Entre los fines específicos por supuesto incluyo la enseñanza de catecismos a los indígenas de la América recién descubierta, o la requerida por las misiones religiosas en Asia.

4 Aunque luego el estructuralismo se encargase de cerrarlas primero y de borrarlas después, fuera de la gramática histórico-comparativa hubo otros intereses como la elaboración de alfabetos fonéticos, la compilación de gramáticas y sistemas ortográficos para las lenguas aborígenes de América del Norte o el diseño de sistemas abstractos de transmisión de información basados en indicios lingüísticos (Morse).

5 Se trata del Diccionario judicial, compilado por J.F.A. [sic.] e impreso en Madrid y del Diccionario razonado de legislación civil, penal, comercial y forense, elaborado este por Joaquín Escriche, autor de varios manuales jurídicos de éxito en la época. 
incomodo que, por lo demás, estando sobre aviso tampoco motivaba mayores incordios. En la mente de todos supongo que estarán los listados de fueros que sustentan buena parte de las revisiones diacrónicas que han tomado el pulso a la evolución de las lenguas románicas. Con ser esta su más frecuente y popular utilidad, tampoco es la única. Otras veces las vetas jurídicas fueron explotadas para misiones menos conocidas, no sé hasta qué punto sorprendentes, aunque sin duda muy valiosas por el peso de sus contribuciones a la lingüística a medio y largo plazo, además en prácticamente todos los niveles de nuestro trabajo científico. La lexicometría arranca en 1897, año en el que J. W. Käding ${ }^{6}$ da a la luz pública su recuento del vocabulario de la lengua alemana. Su intención primordial, como por otra parte queda de manifiesto en ese trabajo, consistía en aportar una referencia lingüística sobre la que sustentar un sistema de trascripción taquigráfica. Esa pretensión lo hizo escorarse claramente en lo temático hacia los ámbitos más directamente vinculados al uso de la taquigrafía, tales como el comercio o la actividad político-legislativa. Treinta años después, en la siguiente fase de desarrollo de la lexicometría, el A Graded Spanish Word (1927) de Milton Buchanan inicia una metodología cualitativamente selectiva para la recogida de materiales, basada en la ponderación de diferentes campos nocionales. No se puede negar que finalmente la ponderación es más aparente que real: de los siete dominios contemplados, cuatro están directamente relacionados con la producción literaria (obras dramáticas, novela, poesía y prosa miscelánea), uno se le aproxima (folclore) y restan tan solo dos, uno encargado de dar cuenta de los textos periodísticos y un segundo reservado para los textos técnicos. A pesar de todo, lo realmente significativo no es tanto la forma última que adquiere esa discriminación temática, como su existencia en sí misma. Desde ese momento, los principales recuentos sincrónicos del vocabulario de una lengua han contemplado la inclusión sistemática de un ponderador cualitativo en sus muestras, una representación lo más ecuánime posible de la realidad que pretendían transcribir a través de su léxico, entre la que no ha faltado una cuota de atención, directa o indirecta, próxima o remota, al derecho o a materias muy afines.

Junto a ese uso de lo jurídico como material, como corpus empírico de referencia, la lexicografía nos lega también diccionarios de términos jurídicos que sí han mantenido una relativa estabilidad durante las últimas décadas. Aunque estas obras se encuentran considerablemente asentadas en la bibliografia al uso, hasta el punto de ir apareciendo y renovándose con periódica constancia, tampoco deben ser consideradas una manifestación de especial confluencia entre intereses lingüísticos y jurídicos. Se diría que son un producto más de la lexicografía consagrada a la redacción de obras específicas, de tecnolectos o de lenguajes de especialidad. De la misma forma que encontramos diccionarios médicos, de economía financiera o de técnicas vitivinícolas, surgen estas obras, de utilidad evidente, pero muy lejanas de alguna forma de aplicación focalizada de la lingüística, menos aún de alguna posible interdisciplinariedad con otras ciencias que girasen en torno a una parcela de la realidad social compartida, la jurídica. Son precisamente estos diccionarios el primer testimonio de la indefinición a la que hacia referencia hace tan solo un instante. Junto a obras que cumplen a grandes rasgos con ese carácter tecnolectal ${ }^{7}$, otros claramente vacilan

6 Para una visión detallada del desarrollo de la lexicometría hasta la moderna versión de la disponibilidad léxica, cf. Mateo (1998).

7 Caso de obras ya clásicas (para el español, Cano Rico, 1980; o, entre otros, Colonna d'Istria, 1985), o de otras más recientes como, sin salirnos del español, el Diccionario Básico Juridico (1993) o, también entre un listado mayor, Fernández Martínez (2002). 
o eligen opciones demasiado puntuales. Unas veces la generosidad en la ampliación de los límites jurídicos termina por difuminarlos, presentando diccionarios en que lo jurídico convive de manera indiscriminada con disciplinas humanísticas diversas ${ }^{8}$. En otras ocasiones, justo en el extremo contrapuesto, la focalización es tan intensa que perdemos de vista una referencia mínimamente abarcadora del conjunto de interrelaciones a los que pueden conducir lenguaje y derecho".

Este punto de mi exposición empieza a conectar con algunas notas básicas de la propuesta que me gustaría discutir aquí. Como he avanzado, pienso que, a diferencia de lo sucedido durante siglos, hoy cada vez más contamos con un dominio de preocupaciones, en principio interdisciplinare ${ }^{10}$, situado en un cruce de caminos, o de materias, en el que convergen las vida de las lenguas y el mundo del derecho en todas sus facetas. Estoy persuadido, además, de que ese dominio lo es en sentido profundo y bidireccional, dado que está siendo transitado desde ambas orientaciones, desde la lingüística hacia las cuestiones jurídicas, pero también desde el derecho hacia los temas relacionados con la vida de las lenguas. En lo que a nosotros concierne, entiendo que ese terreno admite dos vías de ubicación en la configuración disciplinar de la lingüística contemporánea, ya sea en función de la temática abordada, ya de la presencia/ausencia de proyección de los conocimientos lingüísticos sobre la práctica jurídica. Desde el primer ángulo, se inscribiría en dominios netamente descriptivos, analizando las legislaciones responsables de la distribución que adopten las lenguas de un determinado entramado social, por una parte, y, por otra, examinando las reglas sociales que determinan el funcionamiento específico de un tecnolecto, en este caso el jurídico. En ambos supuestos, nos desenvolvemos dentro de ámbitos, predominante, aunque no exclusivamente, sociolingüísticos $^{11}$, matiz que aclararé de inmediato. De otro lado, cuando recurrimos a la lingüística para solventar cualquier urgencia externa, evidentemente, nos desenvolvemos de lleno y sin ambages dentro de los linderos de la lingüística aplicada. Para este cometido, como de hecho quisiera detallar a lo largo de las páginas siguientes, son pertinentes varios ámbitos y enfoques de intervención lingüística, sin mayores restricciones de escuela o preferencias disciplinares.

Pero antes de adentrarme en todo ello, me parece necesario tratar de esbozar al menos, bien que de manera esquemática y somera, algunas de las directrices maestras de ese marco de preocupaciones interdisciplinares.

\section{La mirada lingüística hacia el derecho}

Desde la lingüística, quizá la primera dificultad de envergadura radique en la posibilidad efectiva de encontrar directrices claras, consensuadas e incontrovertibles en lo teórico y en

8 En alemán, Becher (1994) aporta un diccionario jurídico y económico, tradición que por lo demás tampoco era desconocida en otras lenguas como el francés (Giho, Bichot y Martin, 1998).

9 Baste como muestra el diccionario de derecho inmobiliario que aporta Atias en 1989.

10 Sin entrar de momento en la exacta caracterización de esa interdisciplinariedad, sin duda otro de los puntos importantes de esta discusión que también abordaré con mayor detalle de inmediato.

11 Entendiendo este desde un modelo epistemológico abierto e integral que incluya todas las opciones posibles de análisis de la interacción lengua y sociedad. Ello no significa excluir al variacionismo laboviano, aunque sí desembarazarse de su exclusivismo. Sobre mi posición al respecto, diré que en varias ocasiones -y en especial en García Marcos (1999)- he abogado por una perspectiva integral de todas las aportaciones lingüísticas, no solo por su mejor acomodación al fenómeno jurídico, sino por razones epistemológicas de carácter general. 
lo metodológico, incluso aunque no llegaran a ser del todo maestras en pleno sentido del término.

Los intereses lingüísticos por el espacio jurídico, aunque han solido encontrar cobijo entre dominios relativamente amplios de inquietudes lingüísticas, también han actuado de manera harto autónoma. Para algunos, los pasadizos que pueden intercomunicar lingüística y derecho poseen un tinte predominantemente sociolingüístico, en la medida en que plasman un tipo de relación entre lenguaje y sociedad. A pesar de mi biografía científica, no comparto esta opción en su versión maximalista. De aceptarse el carácter redundante del prefijo socio- $^{12}$, como sostiene Labov (1972: 235-323) ${ }^{13}$, simplemente no habría otra lingüística posible. Las leyes, los juicios, el aparato judicial en su totalidad tampoco supondrían nada sustancialmente nuevo al respecto. No obstante, sucede que la caotología y la teoría de los fractales también han llegado a la lingüística y que han convencido a algunos -entre los que me incluyo- de que una perspectiva de estudio, no es la única perspectiva posible. No cabe duda de que hay un componente sociolingüístico importante, muy relevante y quizá el que cuenta con la tradición más sólida dentro de este campo de investigación que, en todo caso, no ha excluido ni las contribuciones de corrientes no sociolingüísticas ni otras eventuales intervenciones que apuntan, de manera muy prometedora por cierto, hacia un futuro, considerablemente más abierto y flexible en lo tocante a nuestro marco disciplinar.

\subsection{Aportaciones clásicas}

El que de momento carezcamos de una demarcación interna unívoca, tampoco presupone que esta sea imposible, ni que se desconozcan los intentos por establecerla hasta ahora. Antes al contrario, las escasas -pero intensas- tentativas desarrolladas al respecto durante las últimas décadas hablan en positivo de tal eventualidad, por más que desde el principio subrayen la enorme y compleja diversidad casuística a la que con toda certeza habremos de enfrentarnos. A pesar de su intermitencia y de su heterogeneidad, ese bagaje pone hoy a nuestra disposición un primer balance sobre cómo los lingüistas nos hemos ido aproximando al derecho y a su mundo. En el fondo, ello no deja de ser una manera de empezar a edificar esa ubicación disciplinar que estamos persiguiendo, desde la propia experiencia científica que hemos sido capaces de acumular.

La primera evidencia, un tanto inquietante por cierto, que nos ofrece dicho balance no es otra que un cierto sentimiento de pertinaz desacuerdo, puesto de manifiesto en el propio rótulo que habría de ser el señuelo identificador de estas preocupaciones. Tanto es así que en la bibliografia circulan varias acuñaciones para referirlas, bien es verdad que bastante acotadas en lo geográfico y dotadas de ciertos matices de contenido algo más que relevantes.

En el mundo anglosajón predomina netamente la referencia a los estudios de Lenguaje y Derecho (Language and Law) o diversas combinaciones de aspectos lingüísticos con el

12 Se sobreentiende que en el vocablo sociolingüística. Para Labov no es concebible ninguna manifestación lingüística ajena a algún grado de socialización, por lo que la sociolingüística es, en realidad, la lingüística en su máxima coherencia con la función humana que la ha desarrollado.

13 Planteamiento que inaugura una lista de reivindicaciones, larvadas y/o explicitísimas según cada autor en concreto, en esa misma dirección. Baste como botón de muestra la contundencia con la que Hudson (1980: 28) ha expulsado a la lingüística ajena a ese prisma, la lingüistica asocial en su terminología, de la lingüística sin adjetivos. 
término legal ${ }^{14}$. El contexto latino-mediterráneo se inclina también de forma mayoritaria por la denominación de lingüistica juridica (linguistique juridique, linguaggio giuridico), tanto en Francia e Italia, como en España, no sin excepciones que de inmediato aludiré. Los lingüistas alemanes, en cambio, han introducido una exuberante diversidad terminológica que, además, no siempre es susceptible de ser catalogada de sinonímica. De un lado encontramos denominaciones muy genéricas, en parte equivalentes a las que acabo de comentar, que se harian cargo de lo que podríamos traducir como lingüística del derecho o lengua y derecho (Sprache und Recht, Rechtslinguistik). El mismo tono abarcador mantendría la de 'comunicación jurídica' (Juristiche Kommunikation) que, en sentido estricto, rebasa incluso nuestro marco disciplinar, abriéndose a perspectivas sobre el papel vinculadas con la semiótica o la teoría de la comunicación. Otras, en cambio, prefieren acotaciones mucho más precisas, como las que sugerirían las de lingüistica forense o a la de tecnolecto jurídico (Fachsprache der Justiz, Forensicher Linguistik). Contra las apariencias, la diversidad en esta ocasión resulta esclarecedora y supone una llamada de atención para discriminar con nitidez los múltiples aspectos, no siempre directamente vinculados, que cubre ese extenso manto que va desde el lenguaje hasta el derecho y/o viceversa. Todo lo anterior, por supuesto, es susceptible de ser integrado como lenguaje y derecho, si bien resulta del mismo modo evidente que cuestiones como la comunicación desarrollada durante los procesos judiciales, las características jergales del derecho o las contribuciones forenses que puedan realizar los lingüistas tienen características demasiado propias y acusadas como para integrarlas de manera indiscriminada -y sin mayores matices- dentro de un apartado común e indeterminado.

$\mathrm{Al}$ margen de fluctuaciones en el etiquetaje último de ese dominio de investigación, contamos con tres grandes tentativas por sistematizarlo, sin olvidar otras aportaciones, no por específicas, menos penetrantes. Concentrándonos en las primeras, y procediendo por orden cronológico, Judith Levi delinea en 1982 tres ámbitos fundamentales de intervenciones lingüísticas dentro del entorno jurídico:

Las que darían cuenta de la lengua propia de las interacciones desarrolladas dentro del mundo judicial.

Las encargadas de examinar los enunciados lingüísticos en la ley.

Las concentradas en la lengua escrita de la ley.

La propia Levi se encargará de precisar con mayor detalle la enorme -también vaga- amplitud de esos epígrafes, proponiendo seis campos de actuación concreta, a su vez subespecificados en múltiples aspectos, ya sí, muy puntuales. Así, la fonética y la fonología podrían contribuir a la identificación de voces o a la detección de los simuladores de voz, entre otros cometidos, la morfología y la sintaxis se encargarían de analizar los modelos de documentos legales o de evaluar las formas de los interrogatorios desarrollados en los juzgados, y la semántica, además de ocuparse de toda la terminología, abordaría las condiciones que permiten establecer como verdadero o como falso un enunciado. A la pragmática, en sentido genérico, le compete el análisis de los discursos en cualquier clase de proceso legal, así como la parametrización objetiva de las ofensas verbales. La sociolingüística, por su parte, estaría encargada de calibrar hasta qué punto el uso del lenguaje es correlato de evaluación 
social y cómo ello puede determinar el proceso, además de toda la problemática vinculada a la sociología de la planificación lingüística. Por último, los problemas de memoria y comprensión del lenguaje legal piensa Levi que son competencia de la psicolingüística.

Diez años después, Grewendorf (1992) mantiene el esqueleto básico de la propuesta de Levi, aunque introduce algunas correcciones a la postre muy determinantes, si no en el fondo de sus planteamientos, sí en la forma que adquieren. Subsume los últimos dos epígrafes del esquema general presentado por Levi, cuya discriminación última nunca resultó suficientemente evidente, en un único apartado, la lengua de la ley, al que seguirán otros dos -la lengua del autor de los hechos y la lengua en el juzgado- para terminar de completar un nueva triada.

Antes, Jacques Cornu (1990) había realizado una propuesta sustancialmente distinta, no sé hasta qué punto menos apriorística, aunque sí cuando menos en apariencia se diría que más internalista, más apegada a una delimitación de lo que a su juicio serían los rasgos fundamentales que delimitan el lenguaje jurídico. De ese modo, considera que la primera particularidad de este es su carácter grupal, circunstancia que de inmediato lo configura como un tecnolecto. Si bien mantiene como elemento definitorio su acusado tradicionalismo, responsable último de su indudable talante arcaico, no deja de ser perceptible en él una cierta evolución, sujeta a condiciones contextuales de peso (como cuando, por ejemplo, sucede una renovación institucional, etc.) o a su propia naturaleza plural, dado que cuenta con diversos estilos que responden a otros tantos campos dentro del derecho (leguaje legislativo, procesal, administrativo, doctrinal, etc.) Esa misma línea, más desembarazada de otras lecturas, más aséptica, si se prefiere más tecnocrática, ha sustentado un buen número de investigaciones empeñadas en caracterizar formalmente el lenguaje jurídico ${ }^{15}$, bien en su conjunto, bien en ámbitos más específicos, tanto en lo temático (lenguaje administrativo, contractual, etc.), como en los recursos lingüísticos empleados en cada ocasión ${ }^{16}$.

Esos tres grandes marcos programáticos recogen e intentan sistematizar la experiencia concreta acumulada en otras indagaciones más singulares que, o bien se han inscrito en otras referencias teóricas, o bien han actuado de manera más aislada, por momentos ocasional. Entre todas estas últimas destacan, por su fehaciente continuidad, el interés mostrado por los etnógrafos del habla hacia la interacción en el mundo jurídico. Esas pesquisas formaban parte de un ambicioso programa de investigación, encaminado fundamentalmente a desentrañar los mecanismos contextuales que determinan el desarrollo de los actos comunicativos ${ }^{17}$. En ese empeño, desde sus primeros balbuceos teóricos, la etnografía del habla siempre ha mostrado interés por encontrar referentes empíricos que refrendasen, refutasen o matizasen sus planteamientos. Para ello ha actuado con enorme sistematicidad, adentrándose en el análisis de una gama extensa y diversificada de eventos comunicativos. A diferencia de otras corrientes sociolingüísticas norteamericanas, desde esta se ha mostrado especial sensibilidad hacia el componente cualitativo de sus pesquisas, lo que se ha traducido en una exigente búsqueda de eventos diferentes. Con esos presupuestos, las restricciones no podían ser más

15 Aguirre y De Larramendi (1997), Alcaraz y Hugues (2002), Ortega Arjonilla et al. (1996), Sánchez Montero (1996).

16 Calvo Ramos (1980), Henríquez y De Paula (1998), Miguel (2000).

17 Esto es, conforme a la definición de estos que aporta Hymes (1974), referimos toda clase de interacciones comunicativas entre individuos. En sus rasgos generales, matices terminológicos al margen, Saville-Troike (1984) y Duranti (1988) mantienen una concepción básicamente similar. 
que mínimas, de producirse realmente alguna, y en consecuencia se ha pasado revista desde la intercomunicación escrita hasta los mensajes de los contestadores automáticos. De entre todos esos tipos de eventos, desde buen comienzo sobresale un acusado y sensible interés por la interacción oral, por las diferentes versiones de lo que tildarán de comunicación cara a cara (face to face communication). Están persuadidos de que el par de adyacencia ${ }^{18}$, la dinámica generada entre quien habla y quien escucha con sus correspondientes intercambios de roles comunicativos, es una atalaya privilegiada desde la que contemplar en su máximo esplendor el evento comunicativo al completo y en condiciones de máxima complejidad. Los contextos profesionales ponían a disposición de los etnógrafos un caso de inmediata y determinante influencia contextual. Prácticamente todo el circuito del evento quedaba condicionado por esa circunstancia, los presupuestos inherentes al ejercicio de una profesión, responsables últimos de activar y caracterizar singularmente todo el dispositivo de comunicación interlingüística ${ }^{19}$. Hacia allí pronto encaminaron sus pesquisas, destacando el interés mostrado principalmente por cuatro campos: el aula, la medicina, el estrado político y el mundo judicial. En relación a este último se hicieron cargo, básicamente, de cuál era la vida comunicativa desarrollada durante los juicios orales, por palpable -y comprensible- determinismo del sistema judicial del que parten, el norteamericano (Charrow y Charrow, 1983; Pousada, 1983). A pesar de que en sus orígenes estuvieran muy identificados con esa dinámica cultural específica, los etnógrafos del habla crearon una tradición en este terreno que, dentro y fuera de su escuela, dentro y fuera de sus seguidores estrictos, se ha extendido también a otras escuelas europeas y, grosso modo, se mantiene vigente hasta nuestros días.

Lo primero que denota una aproximación mínimamente objetiva a esos marcos de comunicación es la palpable asimetría entre quienes participan en ellos, plasmada de manera inmediata en las actuaciones verbales que atestiguan. Hay todo un ejercicio de poder institucional, simbólico y semiótico, pero también lingüístico, que encauza el rumbo y dimensiones que adquiere el propio desarrollo del acto judicial, básicamente ejercido desde los jueces y magistrados. Urge, por tanto, hacernos cargo del rendimiento pragmalingǘstico de sus interacciones ${ }^{20}$, al objeto de calibrar cómo y en qué medida condicionan el desarrollo de la vista. Ello, sin duda, abre la puerta a un conjunto amplio de posibles comportamientos verbales, que alcanzan a todos los participantes en las vistas orales y que, en una u otra medida, pueden llegar a resultar determinantes. Por ahí han desfilado desde el estilo argumentativo mediante el que se presentan pruebas, alegatos y defensas ${ }^{21} \mathrm{o}$ el grado de coherencia táctica al que acuden los letrados (Nofsinger, 1983), hasta la kinésica y la proxémica entre la que se desenvuelven (Philips, 1986), pasando por reflexiones más genéricas sobre las funciones lingüísticas desplegadas (Schröder, 1987), el tipo de estructura dialógica que los caracteriza (Jodlbauer y Wildgen, 1980; Wildgen, 1983) o las interferencias que puedan registrarse en estos eventos comunicativos (Gumperz, 1982).

La pregunta que de inmediato queda pendiente, como es fácil imaginar, no es otra que hasta qué punto todos esos factores condicionan el propio ejercicio de la justicia-esto es,

18 Cfr. al respecto Sacks, Schegloff y Jefferson (1974), fundacionales en esa dirección, y la revisión crítica y constructiva que aporta Goofman (1981).

19 Las relaciones entre los participantes, las formas de los mensajes, el valor simbólico de la escena, etc.

20 Philips (1985), Van Scriver (1985), Harris (1984). Hernández Terrés (1994), Hoffman (1980).

21 Conley, O'Barr y Lind (1978), Fuentes y Villa (2003), Greendorf (1985), Seibert (1977). 
el juzgar objetivamente y conforme a ley-, hasta qué punto son un juicio, o un pre-jui$\mathrm{cio}^{22}$, independiente de la valoración objetiva de los hechos que se someten a examen. Esa inquietud de los etnógrafos del habla se vio complementada por las investigaciones variacionistas, de inmediato trasladadas a estos nuevos cometidos, que pusieron de manifiesto la existencia en toda comunidad de habla de marcas o estereotipos sociolingüísticos negativos que mueven a juicios firmes sobre quienes los usan. De la combinatoria de ambos factores, asimetría comunicativa y estigmatización sociolingüísticas, podrían derivarse actuaciones judiciales demasiado lastradas por condicionamientos ajenos a las propias causas judiciales. En nuestras sociedades a diario circulan individuos marcados negativamente por su manera de expresarse a través de su lengua. Sentarlos en un banquillo supondría juzgarlos sin poder sustraernos, al menos en apariencia, del prejuicio que comporta el uso que realizan de su propia lengua.

Desde Alemania, a pesar de que costó mantener una continuidad escolar manifiesta y explícita, en todo caso se abundó en el análisis crítico, por momentos vindicativo, de esas interacciones. Ruth Leodolter (1975) ha destacado sobremanera en ese empeño, fijando uno de los hitos indiscutibles de estos estudios. Su punto de partida teórico es netamente sociolingüístico -en su versión interaccionalista, por supuesto-, a pesar de que como veremos de inmediato muy pronto en su andadura encontrará la compañía científica de la pragmática y de la psicolingüística. Leodolter retoma la discusión sobre los condicionamientos lingüísticos que acechan a la práctica judicial, inclinándose sin vacilar por una valoración negativa de los mismos. En efecto, como presagiábamos, la forma en que se exprese un acusado puede influir en el veredicto que reciba, desde el momento en que la influencia evaluativa de los marcadores sociolingüísticos es un dato objetivo y, como tal, carece de restricción de entorno de actuación. Si actúan en la calle, en la admisión de un alumno en un centro escolar o en una tienda, por qué no iban a hacerlo también en el juzgado. No obstante, Leodolter no se detiene en la mera constatación de ese hecho, sino que a partir de ahí realiza dos ampliaciones temáticas muy determinantes. Para empezar advierte que no son los únicos elementos que están en condiciones de influir sobre las decisiones judiciales. Lo que en realidad entra en juego es todo el entorno semiótico y psicosocial que envuelve al acusado, como una especie de carné de identidad social, como el poseer, o no, antecedentes penales, etc. Para continuar, extiende esa clase de influencia más allá de la sala de vistas, ante la evidencia de que alcanza prácticamente a toda la vida jurídica. También es preciso detectarla y tipificarla en la narración desarrollada en ámbitos jurídicos, en la interrogación judicial, en las interacciones dialogadas dentro de contextos jurídicos, en las formas de argumentación que se exponen en los juzgados o en la investigación sobre diversos aspectos y recursos sociopragmáticos en la escena jurídica. Ello supone poco menos que plantear todo un programa de investigaciones e intervenciones que tendrá su continuidad en otros autores alemanes posteriores.

Grewendorf (1992) marca el punto culminante en que esas carencias, esas quejas o denuncias, alcanzan una formulación conceptual explícita que, además, abarca a la totalidad del lenguaje jurídico. Para Grewendorf este constituye un exponente de barrera lingüística. Adopta y utiliza un concepto antiguo en la bibliografía sociolingüística alemana, muy vinculado en sus orígenes al análisis del déficit lingüístico bernsteiniano. Conviene recordar 
que en Alemania la discusión de las ideas de Bernstein tuvo una honda repercusión, hasta el punto de que a principios de los 70 traspasó las fronteras del estricto diagnóstico sociolingüístico ${ }^{23}$. En primera instancia, estudios como los de Överman (1972) o Ammon (1972) certificaron en el terreno empírico, una vez más, la existencia de diferencias de potencial comunicativo en los alumnos de estratos humildes, condicionamiento que a la postre lastraba tendencialmente su progresión escolar. Contra la especulación a la que fueron sometidos los planteamientos bernsteinianos, sobre todo en EE. UU., y sobre todo por parte de Labov y sus seguidores, la inmensa masa de datos aportada desde Alemania suponía un refrendo incontestable. Ese refrendo era algo más que un espaldarazo científico, en la medida en que de la detección de déficit lingüístico se seguía la demanda de políticas lingüísticas y sociales que lo erradicasen. Si en el resto del mundo ello supuso abrir una importante trinchera científica e ideológica, en Alemania revistió carácter de auténtica revuelta intelectual, hasta el punto de que la lucha contra las Sprachbarrieren, contra las barreras lingüisticas resultantes del desequilibrio lingüístico contrastado empíricamente, terminó entrando en el Bundestag, a la vez que algunos lingüistas como Wunderlich (1971) vieron en ella el nuevo estilete que destaparía una completa revolución social. La lucha contra las Sprachbarrieren traía aparejada otra revuelta no menos honda y significativa. Las barreras lingüísticas fueron empuñadas por los jóvenes lingüistas de la época, en franca contraposición a la Germanistik, a la tradición académica consolidada y hegemónica en la universidad de aquel país. Tan palpable fue esa contraposición, que hoy muchos de los protagonistas de aquella cruzada científica, social, académica y ética desempeña sus labores profesionales en el área de lingüística, desvinculados incluso académicamente de la filología materna. Así pues, cuando Grewendorf acude al término barreras lingüísticas está realizando una elección cargada de connotaciones y contenidos.

Como digo, Grewendorf supone un momento culminante, de elaboración final que sin embargo no carece, antes al contrario, de precedentes numerosos en cuanto a la pertinencia de enfocar el lenguaje jurídico desde la óptica bernsteiniana ${ }^{24}$. Todos ellos comparten, conforme a una de sus primera formalizaciones expuestas por Badura (1973), la convicción de que sólo puede ser considerada democrática aquella variedad de lenguaje que es común y compartida por la totalidad de los miembros de una sociedad y que, en ese sentido, otorga una suerte de igualdad comunicativa a todos los potenciales interlocutores de la misma. El jurídico se situaría en las antípodas de ese igualitarismo comunicativo que reivindican, desde el momento en que emana del poder político, en que está formulado de manera críptica, en que refleja la ideología dominante y en que, por último, sólo es accesible a un sector profesionalmente especializado. De ese modo, no vacilan en considerarlo uno de los contraejemplos más palmarios a esa comunidad ideal, extensa y uniforme en el uso de una lengua común; más aún, constituiría un exponente indiscutible de recurso lingüístico antidemocrático por excelencia. El problema que plantean es realmente arduo, en la medida en que no estamos abordando solo una actuación lingüística, sino uno de los ejes cardinales

23 En García Marcos (1999) ya he realizado una revisión panorámica, tanto de las teorías de Bernstein, como de su proyección en Alemania, Francia e Italia, a la que ahora remito.

24 Algunos de ellos incluso anteriores a la propia Leodolter. Cf. al respecto Badura (1973), Betz (1975), Dobnig-Jülich (1982), Hengenbarth y Scholz (1979), Kalverkämper (1978), Menne (1975), Northdurf (1987), Oksaar $(1967,1979)$. 
de la vida social. De la antidemocracia del lenguaje empleado por el aparato judicial se sigue, de manera inmediata y fulminante, la de su ejercicio y, por consiguiente, se cuestiona seriamente uno de los grandes pilares que sostienen los sistemas democráticos y, en último término, a estos mismos. Las barreras lingüísticas que introduciría el lenguaje jurídico, por tanto, proceden de la disonancia entre su origen, una casta especializada, y su destino social, la sociedad en su conjunto. Desde el momento en que ha de servir al conjunto del cuerpo social, el sesgo tecnocrático de su origen introduce un desequilibrio que supone un ejercicio de poder desde quien lo ejerce y lo conoce. Como veremos más adelante, no será ni la única vez ni el único dominio disciplinar que ponga sobre el tapete una denuncia en semejantes términos.

Ante tal diagnóstico, de inmediato se propugna una reforma del lenguaje jurídico en sí mismo, así como de las interacciones lingüísticas desarrolladas en el seno de los procesos judiciales. Desde esos presupuestos, la vida lingüística del aparato judicial se percibe en términos netamente conflictivos. Se subraya ahora una de las consecuencias a las que llevaba el examen etnográfico de las interacciones jurídicas. No basta, pues, con describir y conocer cuáles son sus componentes y cómo se interrelacionan, sino que se persigue detectar en qué medida esa constelación comunicativa bloquea la ecuanimidad del proceso judicial y, consecuentemente, sesga las decisiones que desde él se adopten. Reencontramos de nuevo la sala de vistas como uno de los grandes escenarios de investigación ${ }^{25}$, surcada ahora por asimetrías fehacientes que discriminan a sus protagonistas en razón del sexo (Bosmajian, 1983), la variedad vernácula de los encausados ${ }^{26}$, su origen étnico (Pousada, 1979; Rehbein, 1980), su procedencia social (Kalin, 1982) o su edad (Brennan, 1995). Por su uso del lenguaje, las mujeres, los hablantes dialectales, los inmigrantes, los procedentes de estratos humildes y los niños transitan por la peligrosa frontera que separa el tópico del prejuicio, con los ya mencionados condicionamientos negativos que su estado social puede acarrearles al tratar asuntos con la ley. En algunas materias esas limitaciones parecen ser todavía más gravosas, como sucedería en el derecho laboral (Fuentes y Villa, 2003). Una vez más, como cabía esperar, no se vacila en reclamar una profunda e intensa reforma de la vista oral (Hoffman, 1983).

No todas estas aproximaciones lingüísticas al derecho revistieron cariz crítico y reivindicativo. Los lingüistas, alemanes -y no alemanes- también ofrecieron sus conocimientos peritos para la resolución de problemas, bien durante el desarrollo de las investigaciones, bien durante la celebración de los juicios. Las intervenciones más conocidas, también las más espectaculares y en alguna ocasión igualmente las más sangrantes, giraron en torno al reconocimiento de locutores en sus vertientes oral y escrita. En ese epígrafe pronto se integraron los estudios estilísticos, trasladando básicamente metodologías ya conocidas, como la empleada para la identificación de autoría literaria anónima, al de sujetos de los que tenemos conocimiento de su comportamiento verbal y sospechamos que han infringido la ley. En el extremo máximo de formalidad material que supone la escritura, se reclamó igualmente el asesoramiento lingüístico para cometidos grafológicos ${ }^{27}$. Sin embargo fue el

25 Caesar-Wolf (1980), Danet (1980), Grewendorf (1985, 1991), Varaux (1989), O’Barr (1982), Philips (1984), Schütze (1978).

26 Bahrs (1979), Neuman (1992), Podlech (1975), Safford (1977).

27 Conrad y Stier (1989), Haehling (1980), Jöns (1982), Michel (1982, 1990), Slembeck (1981). 
reconocimiento de voces lo que propició los éxitos más aclamados de estas aplicaciones lingüísticas $^{28}$. Como sostiene Brückner (1992) de ese modo el lingüista termina por convertirse poco menos que en un detective, o cuando menos en un comisionado que certifica todo este tipo de prácticas policiales y judiciales (Brinker, 1989), con todo lo que ello comporta. En efecto, las presiones -implícitas, pero también explícitas- a las que pueden verse sometidos los investigadores son considerables y, desde luego, una eventualidad que debe ser controlada, al menos en la medida de lo posible. Como ha recomendado Kniffka en alguna ocasión, es imprescindible realizar esta tarea desde el más absoluto de los secretos profesionales.

Del mismo modo es necesario acompasar el tempo de la investigación con el de la maquinaria de la justicia, para evitar que se repitan casos tan flagrantes como el de Timothy Evans, acusado y condenado erróneamente por la comisión de varios asesinatos, solo aclarados tras el examen lingüístico de su confesión, con nítidos indicios verbales que atestiguaban su veracidad (cf. Crystal, 1987). Los resultados de la revisión lingüística de su caso no evitaron que el perdón le llegase demasiado tarde, ya fallecido.

Otros peritajes revistieron menos compromiso. Se ha tratado de aportar parámetros para calibrar la mentira (Bathia, 1983; Crystal, 1987), retomando una antigua tradición iniciada en Estados Unidos que contó con el apoyo incluso de la propia administración (Serrano, 1981). Otras veces se acotaron los límites exactos de comportamientos verbales susceptibles de ser delictivos, tales como el chantaje (Hehn, 1992) o el insulto (Fuentes González, 1996). En esta ocasión la valoración del lingüista resulta determinante y algo más que orientativa para el juez, dado que permite ajustar con precisión a partir de qué punto estamos dentro, en los límites o fuera de un chantaje, un insulto o una calumnia.

Para concluir, desearía tan solo referirme a la traducción en el mundo jurídico, a caballo entre lo pericial y lo asistencial. En apariencia, el intérprete en el juzgado, desde el punto de vista meramente técnico, tampoco se enfrenta a cometidos sustancialmente distintos a las que desarrollaría en cualquier otro contexto. Sin embargo, como subraya Herrero (1994), la interpretación en estas circunstancias ha de tomar en consideración múltiples precauciones porque no siempre es unívoca. Hay elementos verbales y gestuales con valores culturales contrarios que no pueden ser literalmente interpretados, o de lo contrario se estará configurando un testimonio más propenso a la confusión que al esclarecimiento de los hechos encausados. En ese sentido la interpretación habrá de ser doble, no solo del contenido de las declaraciones efectuadas durante los interrogatorios, sino también del valor lingüístico y paralingüístico de estos testimonios.

La vertiente traductora del dominio jurídico sigue una pauta común a la moderna traductología general, postulándose como una actividad social, y no como un mero producto lingüístico (Hatim, 2001). De ahí deriva un marcado carácter interdisciplinar (Acuyó, 2003; Borja, 2003), defendido como una auténtica seña de identidad epistémica, que recogería la convergencia de aportaciones de la lingüística, el derecho, la sociología o la semiótica. Esa génesis interdisciplinar, en cualquier caso, tampoco entraría en contradicción con el desarro1lo de algunas preocupaciones sustantivas, igualmente comunes al conjunto de la actividad traductora, tales como el problema de la equivalencia, la consideración de la traducción como tercer código, la presencia de elementos interculturales, los aspectos cognoscitivos del 
proceso de traducción jurídica, la ética del profesional de la traducción o el debate sobre control de calidad de la actividad traductora. El apartado lingüístico de esa confluencia de intereses científicos se ha concentrado prioritariamente en la consideración de la traducción jurídica desde el punto de vista del género lingüístico y, subsidiariamente, del transgénero que desplegaría el propio ejercicio traductor ${ }^{29}$.

A pesar de todo, la traducción jurídica no puede soslayar problemas serios de clarificación y definición. En ocasiones se restringe lo lingüístico a lo meramente lexicográfico, sin que incluso dentro de este último aparezcan con nitidez cuáles son sus exactas competencias. No son desconocidos en la bibliografía los diccionarios que unifican lo jurídico y lo económico ${ }^{30}$, sin saber con exactitud a qué obedece una decisión de tal naturaleza, si a una concepción específica de la tarea lexicográfica o a meros condicionamientos de mercados. Quizá por ello empieza a proliferar una investigación muy centrada en situaciones puntuales, indudablemente más acotadas en lo temático, y dotadas de una mayor aplicación inmediata. Monzó (2002) se ha concentrado en el derecho inmobiliario, siguiendo con esa dimensión social de la traducción ya reseñada, Álvarez Jorge (1998) en la traducción de textos legales dentro del ámbito sanitario alemán y español, Acuyó (2003) en la de marcas comerciales, Varela, García Rodríguez y Muñoz (1998) en los contratos de arrendamiento, Castillo González (1998) en la traducción de actas de reuniones o, por no extenderme, Delgado e Infantes (1998) en la de comisiones rogatorias y Martín Hita (1998) en los textos de organizaciones internacionales. Como se puede apreciar todos estos últimos textos pertenecen a un mismo volumen, relativamente reciente, en el que la vertiente jurídica ocupa un modesto capítulo dentro de una panorámica más vasta de la traducción contemporánea en su totalidad, síntoma elocuente de lo fundamental de estas contribuciones, a la vez que de lo mucho todavía pendiente.

\subsection{Nuevas orientaciones}

Con ser prolijo y variado el índice de aspectos abordados hasta este momento, tampoco agota todas las posibles confluencias entre lenguaje y derecho. A partir de los años 90 , una parte de la bibliografia, predominante aunque no exclusivamente sociolingüística, va a hacerse cargo de la situación en la que se encuentran los derechos lingüísticos humanos. Lo que pretenden se evidencia de inmediato, ya que el parangón con sus homólogos de referencia -los derechos humanos, sin más adjetivos- es voluntario. Todo individuo posee unos derechos inalienables, reconocidos por la comunidad internacional, entre los que han de incluirse la capacidad para expresarse libremente, sin que esta se enfrente a restricciones de clase alguna. Ello supone defender hasta sus últimas consecuencias el derecho a expresarse en la lengua materna con independencia de cualquier circunstancia y situación. Cuando ello

29 Tanto es así que algunos de los grandes proyectos internacionales en este campo giran en torno a esta cuestión. Así sucedería en el Generis integrity in Multilingual and Multicultural Settings, coordinado por V. Bathia y C. Candlin, que maneja muestras en trece idiomas (además de cinco variedades de inglés) o el EBMT dirigido por J. Webster. Este último aspira a crear una memoria de traducción juridica basada en textos paralelos alineados con más de 35 millones de palabras. Para más detalles sobre la cuestión del género y el subgénero, Cf. Monzó (2003), Engberg (2002) y Engberg y Wolch (1999).

30 Cfr. a modo de ilustración de cuanto digo para el alemán a Becher (1994), caso que podríamos encontrar en otras lenguas. 
no es así, se estarán violando derechos fundamentales e inherentes a la propia condición humana, por lo que no vacilan en acudir al término de genocidio lingüístico y cultural. Su salvaguarda, al igual que sucede con los derechos fundamentales de los individuos, ha de ser promovida y auspiciada por los organismos internacionales y, en último término, han de constituir un compromiso suscrito por la sociedad civil.

Entretanto se llega a ese gran pacto lingüístico planetario, los sociolingüistas han estado ocupados, prácticamente de manera simultánea, en detectar y denunciar las violaciones de esa parte tan sustantiva de las libertades de todo individuo. Así, han fijado su atención en algunos viejos conocidos de la sociología del lenguaje, entre los que descollan las dificultades arrostradas por las minorías nacionales para mantener sus lenguas en el marco de estados multilingües en los que conviven con otras lenguas mayoritarias y hegemónicas ${ }^{31}$. De la misma forma, han repasado la distribución de los espacios comunicativos internacionales o el grado de efectividad que han tenido las descolonizaciones en materia cultural y lingüística. Como he señalado, todo ello no dejan de ser antiguas inquietudes, ahora revisadas bajo un nuevo prisma y, sin duda, provistas de un impulso académico y social hasta ahora desconocido. Sucede, además, que esa atención hacia la salvaguarda de los derechos humanos en materia lingüística ha escudriñado en el tejido diario de la vida social, ha profundizado intensamente en esa maraña vital hasta alcanzar aspectos ciertamente sutiles. También se ha reivindicado el derecho a elegir el nombre de los hijos, proscrito para los inmigrantes en algunos países asiáticos, o la posibilidad de que las mujeres reciban apellidos, en contra de la práctica común entre algunos colectivos integristas, o la legitimidad de que las enfermeras que atienden a bebés de padres inmigrantes se dirijan a ellos en su lengua materna. La nómina podría ser interminable, entre otros motivos porque crece de manera continua y constante. Más que profundizar en la problemática y casuística de los derechos humanos relacionados con las lenguas, me interesa ahora subrayar que todo este ingente y selectivo trabajo se desarrolla fundamentalmente a través de la revisión de la legislación lingüística vigente. No en vano prácticamente un tercio del volumen que asienta definitivamente esta línea de investigación, compilado por Skutnabb-Kangas y Philipson (1994), está dedicado a ofrecer la base legislativa documental de la que parten, no solo los trabajos que lo integran, sino el conjunto de la investigación susceptible de ser desarrollada en ese terreno. Se abre, por lo tanto, una dimensión hasta ahora desconocida en las relaciones entre lenguaje y derecho que, por lo demás, ha de mostrarse sobremanera atenta a las dimensiones nacionales e internacionales de la legislación, muy en consonancia con los tiempos globalizados que, a gusto o a disgusto, nos han tocado vivir a todos.

Dentro del mismo ámbito sociolingüístico, Etxebarría (1997) contempla la posibilidad, ciertamente sugerente, de abrir un epígrafe específico dentro de la planificación lingüística especializado en el lenguaje jurídico. Sin duda regular los usos lingüísticos del aparato

31 Ni qué decir tiene que ello ha aproximado más que fehacientemente esta moderna investigación sociolingüística con los intereses descriptivos que parte de ella ha mantenido desde sus origenes. En ese sentido, los estudios sobre las múltiples formas de diglosia (cfr. la exhaustiva bibliografia compilada por M. Fernández, 1993) o sobre la situación de las lenguas indígenas, en América y en otras parte del mundo, están indudablemente próximas a cuanto comentamos, aunque no se solapan. Una cosa es describir la asimétrica situación sociolingüística que viven esas lenguas (cfr., González y Rodríguez, 2000, por mencionar un volumen emblemático al respecto) y otra denunciar esa situación, hacer explícitos los derechos que se vulneran y proponer intervenciones alternativas (cfr. De Varennes, 1996). 
judicial, se diría que es una obligación poco menos que ineludible para una sociedad democrática, desde el momento en que garantiza, o amortigua, la posible existencia de barreras lingüísticas que, como sabemos, condicionen negativamente la propia dinámica judicial.

La planificación lingüística no es, en cualquier caso, la única posibilidad que cabe contemplar de cara a un futuro más o menos inmediato. Como sus propios mentores se han encargado de puntualizar, el reciente Análisis Crítico del Discurso conjuga una nueva perspectiva del hecho lingüístico con un compromiso social explícito por parte del lingüista que examina las actuaciones discursivas de las sociedades ${ }^{32}$. Ese examen parte de considerar que en toda acción discursiva se simultanean un texto, una práctica discursiva y una práctica social (Fairclough, 1992: 4). Desde esa tríada aspiran a observar críticamente cómo mediante el discurso se legitima la ideología dominante, a la vez que determinados discursos refuerzan también el orden social y, en último término, la construcción de la identidad subjetiva de los sujetos en tanto que miembros de una colectividad. Ni que decir tiene que en ese entramado hay múltiples aspectos del universo jurídico más que sugerente para esos cometidos lingüísticos. En Martín Rojo, Pardo y Whittaker (1988) o Fairclough, (1998) encontramos panorámicas que dan razón de cuanto acabo de comentar, así como un listado de trabajos que ya han profundizado en el dominio parlamentario o en actuaciones judiciales ${ }^{33}$. Lo que yo desearía subrayar ahora es la línea de continuidad que estas investigaciones establecen respecto de las contribuciones sociolingüísticas alemanas de los años 70 . Bien es verdad que el Análisis Crítico del Discurso actualiza y depura ostensiblemente la metodología entonces empleada y que, en último término, inscribe las reflexiones sobre los dominios jurídicos en una lectura mucho más amplia, no solo de la dinámica social, sino del rol desempeñado por el lenguaje en ella. Con todo, a mi juicio no deja de testimoniar cómo una apuesta científica $-\mathrm{y}$, por qué no reconocerlo, también social- de mediano calado ha encontrado un camino de proyección disciplinar que, en definitiva, corrobora en gran medida lo que entonces no dejaban de ser hipótesis teóricas y metodológicas.

\section{La mirada jurídica hacia el lenguaje}

Como ya ha quedado al menos apuntado en varias ocasiones, esta aproximación de inquietudes científicas que nos viene ocupando es indudablemente bidireccional y, yo me atrevería a agregar, que creciente y progresivamente intensa. A los juristas y estudiosos del derecho, sobre todo al abordar las relaciones que este mantiene con la sociedad, no les ha pasado desapercibida la importancia capital del lenguaje en su ámbito profesional. Toda esa actividad $^{34}$ se podría condensar en la afortunada acuñación que da título a una obra pionera

\footnotetext{
32 Yo diría que la mayor novedad relativa de ese binomio radica en lo explícito del compromiso adoptado por el científico, por el lingüista en esta ocasión. Se trata de una novedad relativa en la medida en que tampoco es la primera vez que los lingüistas confiesan abiertamente sus intenciones sociales, cuando menos desde que la lingüística dinámica irrumpe a partir de los años 60 . Los sociolingüistas bernsteinianos, buena parte de los autores italianos o diferentes escuelas actuales en Europa e Hispanoamérica parten de posiciones inequivocamente comprometidas con una lectura crítica y constructiva de la realidad social. Sucede, en todo caso, que para mí, cuando ese nexo entre la epistemología y la deontología no se manifiesta, tampoco diría que deje de existir, o que no haya existido nunca. Los científicos que hacen dejación de sus responsabilidades sociales, desde luego que realizan una apuesta ideológica de no menor enjundia que aquellos situados en el extremo formalmente opuesto.
}

33 Cfr. las monografías de Carbó $(1984,1995)$ sobre los discursos político-parlamentarios en México.

34 Cfr. en español Atienza (1985), Atienza y Badenes (1973), Hernández-Gil (1987), Iturralde Sesma (1989), Martín del Burgo (2000), Prieto de Pedro (1991) o Ruiz Vadillo (1991). 
en esta dirección, conforme a la que considerariamos el derecho como una forma de lenguaje (Capella, 1968). En fechas más recientes, aunque dentro de esa misma concepción, lo que ha dado en llamarse enfoque iurilingüístico, (Sarcevic, 1997) considera que el factor lingüístico hace posible un auténtico ejercicio de derecho comparado, sobre todo mediante la traducción.

No obstante, en ocasiones se ha sido considerablemente más explícito a la hora de juzgar, no solo esos vínculos, sino su alcance en la vida social. Desde mediados de la década de los 80 tenemos consolidadas varias llamadas de atención sobre el ejercicio ideológico que desempeña el aparato judicial a través de su comportamiento lingüístico en sentido amplio ${ }^{35}$. En esa época está fechada una de las contribuciones clásicas al respecto firmada por Pietro Barcellona (1988) ${ }^{36}$. Para Barcellona el lenguaje de las leyes supone un gran enmascaramiento ideológico, bajo la apariencia de objetividad de un tecnolecto, el jurídico en este caso. Merced a esa supuesta asepsia que le otorga su carácter técnico, se le presupone un perfil universal y ecuánime, indiscutido por parte de la colectividad, que no hace otra cosa que ocultar su real origen, anclado en una sociedad dominada por el mercado y el beneficio económico, de cuyos intereses realmente emana. Eso explica su vaguedad, esa indefinición del lenguaje de la ley (Luzzati, 1990) que, a la vez, sustenta ese cometido hermenéutico del profesional del derecho al que me referí al principio. Su ejemplar corrección y su indefinición, sobre el papel, lo habilitan para ser objeto de múltiples y variadas interpretaciones. Sin embargo, la práctica jurídica muestra que solo algunas son admisibles y, de entre estas, otra segunda minoría, elegida, afortunada o especialmente perita, finalmente alcanzará el éxito. No sorprende, pues, que el lenguaje de los jueces (Solan, 1993) sea fuente de atención social, de ejercicio del poder en el más prosaico sentido del término, mucho más del mero ejercicio judicial del que participan.

Los juristas han percibido igualmente el enorme abismo que separa a la sociedad civil del ejercicio del derecho. Se han percatado de que en el fondo del mismo también discurre el factor lingüístico. No es de extrañar, pues, que en el marco de una fundamentación más amplia de la filosofia del derecho, Galindo (1993) mire hacia las cuestiones del lenguaje como un imperativo de adecuación de la práctica jurídica a un mundo cada vez más complejo y más precisado de atención, como una manera de responder satisfactoriamente a las demandas y expectativas sociales depositadas en él.

Fuera de ese marco de referencias globales, los ejemplos puntuales vuelven a ser ricos, prolijos, y esta vez bastante sorprendentes, cuando menos en lo tocante a nuestro conocimiento de esas aportaciones. Por lo general los lingüistas nos conformamos con referencias

35 Aarnio (1995), Pardo (1992), Iturralde (1989), Galindo (1993, 1996), Bulygin (1983), Carrió (1979), Olivercroma (1962). Con anterioridad existen precedentes más aislados, aunque muy significativos, de esos vínculos ideológicos (cf. Gobernado, 1978).

36 Barcellona es, muy probablemente, el autor más significativo y reconocido al respecto. No obstante, la sociolingüística italiana siempre se ha sentido muy sensible a todas las manifestaciones institucionalizadas, en una $u$ otra medida, de las lenguas. No solo el mundo jurídico, también el cine, la televisión, el parlamento, el fútbol o, por supuesto, las aulas han desfilado por las páginas de un modelo como el sociolingüístico que, desde su mismo arranque, se configura desde una originalidad sustancial, vivamente interesado por encontrar terrenos de encuentro entre disciplinas. Como quiera que tampoco es mi intención aquí detenerme en un dominio que, por lo demás, excede las pretensiones de este trabajo, simplemente remitiré a algunas referencias fundamentales de los sociolingüistas italianos. Al respecto, cf. Bazzanella (1980), Berruto (1986), Braga (1961, 1969, 1970), Cardona (1987), De Mauro $(1963,1977)$. Por mi parte, me he ocupado de todo ello en García Marcos (1999). 
como las anteriores, suficientes para justificar el carácter interdisciplinar de las pesquisas que estamos proponiendo. No obstante, la propia tradición jurídica es mucho más extensa en lo tocante a inquietudes lingüísticas y, por momentos, me atrevería a decir que también bastante más atractiva. Toda esa bibliografía pone de manifiesto un nuevo interés, no tanto del lenguaje en el aparato legal, como de las leyes sobre el lenguaje. Las lenguas, lo hemos referido en varias ocasiones ya, son instrumentos de la actividad legal, pero también hay actividad legal sobre las lenguas, también hay decisiones que determinan la vida de las lenguas y, por consiguiente, la convivencia cultural y social entre sus hablantes. La legislación lingüística abre un campo de estudio que va más allá de la mera constatación de cómo las sociedades han regulado, y regulan, los perfiles sociales de su principal herramienta de comunicación. No soy precisamente un entusiasta del herderianismo y sus derivados Ello no obsta para reconocer su enorme e indiscutible valor como presupuesto psicosocial prácticamente desde el siglo XVIII hasta nuestros días. Lo de menos es que científicamente se nos antoje infundada, o cuestionabilísima, la pretensión de identificar una lengua con una cultura y ambas con el sostén nuclear de la identidad nacional. Lo determinante es que para amplísimos sectores de la población esto es una verdad incontestable, forma parte de lo consabido. Desde ese punto de vista indagar en la legislación sobre las lenguas es, evidentemente, hacerse cargo de una de las grandes fibras de la más delicada sensibilidad social, al mismo tiempo también de una de las grandes trincheras culturales del mundo contemporáneo, con sus correspondientes vencedores y vencidos. Por eso se repasa cuál ha sido la regulación legal de la convivencia de lenguas en prácticamente todo el mundo, en qué lugar han quedado las minorías de cualquier clase (étnicas, nacionales, religiosas o inmigradas), qué clase de cobertura cultural y lingüística se les otorga, cómo esa legislación va calando en la vida cotidiana, desde la siempre omnipresente preocupación por la situación en el aparato escolar hasta la práctica sanitaria en los hospitales. A veces averiguar cómo se ha reglado la cuestión lingüística se convierte en una llave capaz de abrir el cofre que guarda celosos secretos históricos (como la conformación de los grandes espacios culturales nacionales), junto con modestas joyas (como la influencia que han ejercido las leyes lingüísticas sobre el comercio internacional; cfr. De Varennes, 1996).

Para hacer frente a esos cometidos, una vez más se hace acopio diversificado y no restrictivo de fuentes. Se ha recurrido a constituciones y a grandes tratados internacionales, a corpus doctrinales completos, responsables de haber establecido los márgenes comunicativos de las escuelas y las administraciones públicas, sin desdeñar las ordenanzas municipales o los decretos de los condados norteamericanos, las normativas locales, los reglamentos de los centros públicos $\mathrm{y}$, sobre todo, las sentencias que han tocado directa o indirectamente aspectos relacionados con las lenguas. Estas últimas aportaban, sin duda, el dato valioso, no solo de acogerse a una legislación vigente, y por tanto testimoniarla, sino de ser un exponente de hasta qué punto las sociedades han estado dispuestas a aplicarla y en qué grado. Tan apretado panorama empírico ha terminado configurando interesantes compilaciones de legislación lingüística, de las que da cuenta De Varennes (1996), en un volumen de por sí excepcional que, entre otras virtudes, contiene una rigurosa guía bibliográfica y que, por lo demás, presenta en sus apéndices una valiosa antología de documentos legales sobre minorías lingüísticas y derechos humanos.

A pesar de que toda esta producción científica nunca ha operado desde una conciencia ni próxima ni remota que la vinculase en grado alguno a la lingüística jurídica, ni en sentido 
estricto a ningún otro etiquetaje al uso, sí que en mi opinión contribuye a cerrar el índice de cuestiones que atañen a la interrelación entre lengua y derecho.

Llegados a este punto, los límites que la sociolingüística ocupa en la versión lingüística de los derechos humanos se atenúan indefectiblemente, se difuminan, se borran. En esa bruma compartida probablemente esté gestándose el inicio de la interdisciplinariedad real que andamos persiguiendo, ya durante un par de décadas.

\section{Apuntes provisionales sobre lengua y derecho, a modo de conclusión}

Para concluir tan solo desearía apuntar una propuesta sobre la perspectiva interdisciplinar que considero más apropiada y, en la medida de lo posible, contribuir breve y modestamente a lo que entiendo como una urgencia: la delimitación de una taxonomía actualizada de los estudios de derecho y lenguaje.

Empezando precisamente por esta última, la bibliografía de la que hoy disponemos ha determinado tres grandes dominios de interrelación entre lengua y derecho situados en torno a las legislaciones vigentes, los procesos judiciales y los peritajes lingüísticos. El primero de ellos se bifurcaría a su vez en dos grandes apartados. Uno dedicado a revisar la legislación lingüística, y en su caso a proponer las reivindicaciones que se estimen convenientes en la línea de la defensa de los derechos humanos; otro más decantado hacia el lenguaje de las leyes, en lo que sin duda será uno de los grandes ejes transversales de este campo disciplinar, cuyo denominador común giraría en torno a la caracterización del componente verbal empleado en todo el aparato judicial.

El segundo epígrafe es, por supuesto, el más denso y por momentos también el más conflictivo. El proceso judicial despliega un radio de acción ciertamente amplio y diversificado que cubriría desde un testimonio en el juzgado, una diligencia o un apremio de embargo por vía judicial, hasta una vista oral o el fallo de una sentencia. Con todo, esa enorme diversidad comparte un factor estable, un denominador común, como es la utilización de un lenguaje con alto valor simbólico y connotativo, responsable del rumbo y desarrollo de ese proceso, ritualizado, jergal, poco menos que quasi-secreto. Nuestro eje transversal, cómo no, vuelve a aparecer en este punto para hacerse cargo de la caracterización lingüística del tecnolecto jurídico, así como de las funciones sociales que desempeña.

Ese tecnolecto, en cualquier caso, se ejerce en eventos comunicativos concretos, sujetos a condicionamientos internos, pero también externos. Junto a la transitadísima atención hacia la sala de vistas, sus roles comunicativos y sus potenciales procesos de estigmatización, conviene no olvidar todo el componente escrito de la actividad judicial, no menos determinante en algunas tradiciones jurídicas, como la española sin ir más lejos.

Por último, no hace falta insistir en el papel que los lingüistas pueden desempeñar en los peritajes que se aporten a la revisión de las causas judiciales, porque son un hecho cada vez más frecuente. Sí que no está de más insistir en que para desarrollar esa tarea con independencia es necesario contar con garantías que aseguren la suficiente autonomía de los peritos lingüísticos, aspecto en el que, como ha quedado dicho, viene insistiendo desde hace años la escuela alemana.

El campo de investigación que se nos abre tradicionalmente ha sido catalogado de interdisciplinar, tanto desde el derecho como desde la lingüística. Sin que sea necesario movernos fuera de España, así se colige de lo sugerido por Fernando Galindo (1993) o por Fuen- 
tes González (1996). Parece esta, desde luego, una opción razonable y hasta recomendable, no por ello exenta de algunas matizaciones. Para Galindo, la propia complejidad de la materia sometida a estudio es un importante agente de multidisciplinaridad, aunque no es el más decisivo. Esta responsabilidad le competería a la propia coyuntura contemporánea del mundo jurídico, cada vez más precisado de satisfacer a todos los participantes en los conflictos sociales. En esa dinámica, el lenguaje puede ser, indudablemente, un elemento mediador decisivo que, en todo caso, no debe hacernos perder de vista que estamos ante una lectura de la convergencia disciplinar orientada hacia fines sociales muy concretos, y muy ligados con la vida jurídica. Para Fuentes, la interdisciplinariedad se formula como un gesto de coherencia con la sociedad en la que nos desenvolvemos y con las principales notas definitorias que a su juicio van a delimitar el paradigma científico del siglo XXI; esto es, la interpretación múltiple y complementaria de la realidad. En el caso concreto que nos ocupa, ello quedaría plasmado en las diferentes aproximaciones que se han realizado al hecho jurídico por los sociolingüistas, en primera instancia, pero también, por la pragmática, la gramática del texto o incluso los historiadores de la lengua. Es evidente que ahora nos desenvolvemos, más que en un terreno interdisciplinar, en un dominio netamente intradisciplinar. Pero esta aparente contradicción, pienso que sin embargo es muy productiva para fijar el alcance exacto de la interdisciplinariedad que los lingüistas buscamos, en este caso específico y probablemente también en otros. Durante muchos años la mera mención del término provocaba negros reparos, serias admoniciones académicas y academicistas unas veces, mientras que otras constituía una especie de sortilegio que aproximaba a un futuro mejor, más abierto y más moderno. Por supuesto que tan extremas posiciones, de un lado, distorsionaban la realidad y, de otro, sobre todo se explicaban en función de la existencia de dos núcleos intelectuales antagónicamente enfrentados. La interdisciplinariedad, o la multidisciplinariedad, era prometedora y moderna en la medida en que molestaba y era refutada por la tradición lingüística, y viceversa. El tiempo que ha transcurrido desde entonces, y en especial la bibliografia que con ese marbete se ha ido acumulando, probablemente nos permiten ser hoy más ecuánimes y, por qué no reconocerlo, más críticamente constructivos. Sí, en ocasiones la interdisciplinariedad supuso otorgar un pasaporte franco al diletantismo recubierto de falsa modernidad. Bien es cierto que algunas materias parecían más abocadas a ello que otras. En la reordenación epistemológica de las disciplinas humanísticas vivida a lo largo del siglo XX, antropólogos, filósofos o historiadores, entre otros, han asistido a una transformación muy seria y profunda de su campo científico. Un historiador moderno, además de las fechas y los personajes, se ocupa de la consabida vida cotidiana, pero también de las funciones sociales que desarrollan las lenguas, de la configuración de imaginarios, o de las recetas de cocina de una época, como una manera de analizar la evolución de la cultura de un pueblo. En esos ámbitos la interdisciplinaridad precisa de límites ciertamente laxos. No es el caso de la lingüística, donde esa laxitud mal entendida sí es diletantismo manifiesto. Durante la primera mitad del pasado siglo, la lingüística consiguió delinear y asentar un núcleo reconocible, estable y consolidado, que no movía a mayores dudas acerca de su identidad científica plenamente configurada. A partir de la segunda procedió a ampliarlo, incorporando notas tan consustanciales a su objeto de estudio como todo el componente dinámico, con la consiguiente atención pormenorizada al uso de las lenguas. Cierto es que esa ampliación, como ya preveía Halliday en 1978, rondaba por áreas próximas a las de otras preocupaciones disciplinares, aunque no menos verdad es que derivaba de rasgos 
consustanciales a la propia naturaleza del lenguaje, a su función como vehículo y basamento de múltiples actividades humanas. Si aceptamos que el lenguaje es la condición sine qua non de la conformación de sociedades, que determina la cognición, que ha sido el gran motor evolutivo de las especies, y en especial de la humana o, entre otras cosas, que contribuye a delinear una cultura, por fuerza los intereses de la lingüística coincidirán como mínimo, o convergerán como máximo, en algunos aspectos con los de sociólogos, psicólogos, biogenetistas o antropólogos. Hay que reconocer que durante años hemos renunciado a esas fronteras, tan nuestras como de los colegas científicos que estaban al otro lado de esa imaginaria línea de delimitación. Era una renuncia explicable, por lejana de los estrictos cometidos de fundamentación disciplinar que acompañaron a la época de predominio estructuralista y generativista. Pero transcurrido ese tiempo, esa fase de nuestra trayectoria científica, nada impide que sean retomados serenamente, en el supuesto de que esas fronteras existan de verdad. Cada vez más, se impone una concepción abierta de los objetos que estudiamos, si vamos aceptando que ni las ciencias exactas son segmentables y escrupulosamente discretas, sino más bien manchas sin límites fijos, fractales que condensan varias lecturas posibles de un mismo fenómeno en función de la lente adoptada para observarlo. Cuando estamos viviendo todo eso de manera creciente en el panorama científico contemporáneo, quizá tampoco sería descabellado aplicar la caotología a la delimitación de la topología científica. Para calibrar en profundidad las capacidades que pudo desarrollar el Homo Antecesor de Atapuerca, un eslabón fundamental entre el Homo Ergaster africano y sus más que posibles descendientes europeos, ciertamente requerimos de la participación de arqueólogos, biólogos y lingüistas, como mínimo. Esta sí es una parcela netamente disciplinar, sin puntualizaciones, circunstancia que no evita adoptar una última precaución metodológica para evitar nuevas mutaciones del diletantismo que siempre acecha. Cuando hablamos de interdisciplinariedad, en realidad nos estamos refiriendo a una ampliación de los procedimientos científicos. Existe una primera fase exclusivamente monodisciplinar, por completo exigente desde los presupuestos de cada una de las disciplinas implicadas, para a continuación proceder a realizar una lectura complementaria de datos, accediendo a un segundo nivel interpretativo que resultaría imposible desde cada una de las respectivas singularidades disciplinares. Dicho de manera gráfica acudiendo al ejemplo anterior, para aportar conocimiento lingüístico sobre el Homo Antecesor precisamos operar, de partida, desde la lingüística más estricta para, desde ahí, confrontar, cruzar, combinar, interrelacionar información. En ese sentido, no termino de ver muy claro el grado de interdisciplinariedad que podemos mantener con los juristas. Tal vez sí sea posible en lo tocante a la legislación lingüística, como de hecho ya está sucediendo. Pero fuera de eso, en las otras dos áreas restantes pienso que en realidad estamos ante una aplicación exclusiva de la lingüística, ofreciendo peritajes que sólo esta puede realizar con garantías de cientificismo máxima o, por otro lado, evaluando una clase de entorno comunicativo y extrayendo las pertinentes conclusiones. En consecuencia, considero socorrido, no sé si útil, plantear esa mirada mutua en términos mucho más flexibles. Por mi parte, preferiría hablar de un gran dominio temático, el que comparten lenguaje y derecho, al que concurrirían como mínimo dos disciplinas científ$\operatorname{cas}^{37}$, que unas veces mantienen relaciones interdisciplinares, mientras que otras se desen- 
vuelven en las posibilidades de aplicación que les habilitan sus respectivas epistemologías. $\mathrm{La}$ ciencia, como la realidad, difícilmente es tan uniforme como desearíamos desde nuestros laboratorios.

\section{Referencias bibliográficas}

Aarnio, A. (1995): Derecho, racionalidad y comunicación social. México, Fontamara, trad. esp. de P. Larrañaga.

Acuyó, C. (2003): La traducción de documentos del derecho de marcas: aspectos juridicos, profesionales y textuales. Tesis Doctoral inédita, Universidad de Granada.

Aguirre, B. y H. de Larramendi (1997): Lenguaje juridico. Madrid, SGEL.

Alcaraz Baró, E. y B. Hugues (2002): El español juridico. Barcelona, Ariel.

Álvarez Jorge, E. (1998): "Características de la traducción de textos normativos del ámbito de la seguridad social del alemán al español". En Félix Fernández, L. y E. Ortega Arjonilla. (eds.), págs. $851-861$.

Atias, C. (1989): Lexique de droit inmobilier. París, Dalloz.

Atienza, M. (1985): Introducción al derecho. Barcelona, Barcanova.

Ammon, U. (1972): Dialekt, soziale Ungleichheit und Schule. Basilea, Beltz.

Badenes, R. (1973): "Lenguaje y derecho", Revista jurídica de Cataluña, 1, págs. 25-42.

Badura, B. (1973): Sprachbarrieren. Zur Soziologie der Kommunikation. Stuttgart, Fromann.

Bahrs, A. (1979): Die Vulgärlüge in der juristischen Praxis. Berlín, Duncker-Humboldt.

Baldwin, J. (1977): "The forensics application of phonetic", Police Review, 18th. November, 1609.

Baldwin, J. (1979): "Phonetics and speakers identification", Medecine, Science and the Law, 19/4, págs. 231-232.

Baldwin, J. (1993): Forensic Phonetics. Londres, Pinter.

Barcellona, P. (1988): "Comunicazione e prescrizione nel linguaggio giuridico". En AA. VV.: Comunicazione e linguaggio. Milán, Angelli, págs. 57-69.

Bathia, V. K. (1987): "Language of the Law", Language Teaching, 20, págs. 227-234.

Bazzanella, C. (1980): La sociolinguistica in clasee. Problemi e ricerche nella scuola media dell'obligo. Roma, Bulzoni

Becher, H. J. (1994): Vörterbuch der Rechts-und Wirtschaftsprache. Munich, Hueber.

Berruto, G. (1986): La variabilità sociale della lingua. Turin, Loescher.

Betz, W. (ed.) (1975): Sprachkritik. Zurich.

Borja, A. (2000): El texto jurídico inglés y su traducción al español. Barcelona, Ariel.

Borja, A. (2003): "Investigación en traducción jurídica". En García Peinado, M. A. y E. Ortega Arjonilla, (eds.): Panorama actual de la investigación en traducción e interpretación. Granada, Atrio, págs. 415-427.

Bosmajian, H. (1977): "Sexism in the language of legislatures and courts". En A. P. Nilsen (ed.), Sexism and language. Urbana, National Council of Teachers of English, págs. 131-142.

Braga, G. (1961): Comunicazione e società. Milán, Agnelli.

Braga, G. (1969): La comunicazione sociale. Turín, ERI.

Braga, G. (1970): Il sistema della communicazione come construto mediatore fra società e linguaggio. Roma, Publicazioni dell'Instituto L. Sturzo.

Brennan, M. (1995): "The discours of denial: Crosse-examining child victim witnesses", Journal of Pragmatics, 23, págs. 71-91.

Brinker, K. (1989): "Linguistische Texanalyse und forensicher Textvergleich". En Bundeskriminalamt, ed. Symposium forensicher linguistische Texvergleich. Wiesbaden, págs. 9-18. 
Brückner, T. (1992): "Der Linguist als Fahnder -ratlos aber rege. Zur kritik der forensischen Textvergleich". En Grewendorf (ed.), págs. 230-271.

Bülow, E. y R.-H. Schneider. (1981): Materialen zu einer Bibliographie der Rechtslinguistik. Münster, Inst. Für Allgemeine Sprachwissenschaft der Westf., Wilhelms Univ.

Bulygin, E. (1983): El lenguaje del derecho. Buenos Aires, Abeledo-Perrot.

Caesar-Wolf, B. y L Breuning. (1980): "Zur Analyse von verbalen Interaktionsprozesen in gerichtlichen Verfahren am Beispiel einer Zeugenvernehmung in Zivilprozess". En Loccuner Protokolle, 31, págs. 17-66.

Cano Rico, J. R. (1980): Diccionario de Derecho. Madrid, Tecnos.

Capella, J. R. (1968): El Derecho como lenguaje. Barcelona, Ariel.

Calvo Ramos, L. (1980): Introducción al estudio del lenguaje administrativo. Madrid, Gredos.

Carbó, T. (1984): Discurso político: lectura y análisis. México, D. F., Cuadernos de la Casa Chata.

Carbó, T. (1995): El discurso parlamentario mexicano entre 1920 y 1950. México, D. F., CIESAS.

Cardona, G. (1987): Introduzione alla sociolinguistica. Turín, Loescher.

Carrió, G. R. (1979): Notas sobre derecho y lenguaje. Buenos Aires, Abeledo-Perrot

Castillo González, F. (1998): "La traducción de actas de reuniones" en Félix Fernández, L. y E. Ortega Arjonilla (eds.), págs. 873-879.

Charrow, V. R. y R. P. Charrow. (1983): "Characteristics of the Language of Jury Instructions". En Craig, R. T. y K. Tracy. (eds.): Conversational Coherence. Form, Structure and Strategy. Beverly Hills, Sage, págs. 163-185.

Colonna d'Istria. G. (1995): Diccionario de términos juridicos. Madrid, Acento.

Conley, J. M., W. O'Barr y E. A. Lind (1978): “The power of language. Presentational Style of Jury Courtroom", Duke Law journal, Vol. 1978, pág. 6.

Conrad, W. y B. Stier (eds.) (1989): Grundlagen, Methoden und Ergebnisse der forensischen Schriftuntersuchung.Festschrifts für Lothar Michel. Lübeck, Schmidt-Römhild.

Gornu, G. (1987): Vocabulaire juridique. París, PUF.

Gornu, G. (1990): Linguistique juridique. París, Montchrestien.

Crystal, D. (1987): Applied Sociolinguistics. Oxford, Blackwell.

Danet, B. (1980): "Language in the courtroom". En Giles, H.; W. P. Robinson y Ph. P. Smith (eds.), Language: social psichological perspectives. Oxford, Pergamon, págs. 367-376.

Delgado, T. (1998): “Comisión rogatoria: un abanico de posibilidades” en Félix Fernández, L. y E. Ortega Arjonilla (eds.), págs. 870-885.

De Mauro, T. (1963): Storia linguistica dell'Italia unita. Bari, Laterza.

De Mauro, T. (1977): Le parole e i fatti. Roma, Editori Reuniti.

De Varennes, F. (1996): Language, Minorities and Human Rights. La Haya, Martinus Nijhoff.

Diccionario Básico Jurídico. (1993): Granada, Comares.

Diccionario Jurídico. (1994): Madrid, Espasa-Calpe.

Dittmar, N. (1973): Soziolinguistik. Exemplarische und kritische Darstellung ihrer Theorie, Empirie und Anwendung. Frankfurt, Athenäum.

Dobnig-Jülich, E. (1982): "Fachsprachbarrieren. Überlengungen zur Kluft zwischen Fachsprache und Gemeinsprache als Beispiel juristischen Texte”. En B. Gajek y E. Wedel (eds.), Gebrauchsliteratur, Interferenz, Kontrastivität. Frankfurt, Lang, págs. 313-360.

Dobnig-Jülich, E. (1985): "Vom Juristen-Deutsch. Untersuchungeng und Überlengungen zum 1000 jährigen Bestehen eines Vorurteils". En Germanistink-Forschungestand und Perspektiven, 1984. Berlín, De Gruyter, págs. 325-345.

Duranti, A. (1997): Linguistic Anthropology. Cambridge, Cambridge U.P.

Etxebarría, M. (1997): “El lenguaje jurídico y administrativo. Propuestas para su modernización y normalización”, Revista Española de Lingüistica, 27/2, págs. 341-380.

Engberg, J. (2002): "Legal meaning assumptions. What are the consequences for legal interpretation and legal translation?", International Journal for the Semiotics of Law, 15, págs. 357-388. 
Engberg, J. y K Wolch. (1999): “Genre Análisis of Legal Discourse”, Hermes Journal of Linguistics, 22.

Fairclough, N. (1992): Discourse and social change. Cambridge, Polity Press.

Fairclough, N. (1998): "Propuestas para un nuevo programa de investigación en Análisis Crítico del Discurso". Rojo y Whittaker (eds.), págs. 35-55.

Fant, G. y M. A. A. Tatham. (1975): Auditory Análisis and Perception of Speech. Londres, Academic Press.

Félix Fernández, L. y E. Ortega Arjonilla. (eds.) (1998): II Estudios sobre traducción e interpretación. Málaga, Universidad de Málaga.

Fernández, M. (1993): Diglosia. A Comprehensive Bibliography. 1960-1990. Amsterdam, Benjamins. Fernández Martinez, J. M. (dir.) (2002): Diccionario juridico. Madrid, Aranzadi.

Fuentes González, D. (1996): "La lingüística forense en el contexto ideológico contemporáneo". En Luque Durán, J. de D. y A. Pamies Bertrán (eds.): Primer Simposio de Historiografia Lingüística. Granada, Método, págs. 59-65.

Fuentes González, D. y F. Villa (2003): "Más aportaciones a la lingüística forense: aspectos comunicativos y sociolingüísticos en el ámbito jurídico de lo cultural". En Muñoz, M. D.; A. I. RodríguezPiñero, G. Fernández y V. Benítez (eds.): Actas del IV Congreso de Lingúística General. Cádiz, Universidad de Cádiz, Vol. III, págs. 1115-1141.

Galindo, F. (1993): El acceso a textos jurídicos. Introducción práctica a la filosofía del derecho. Zaragoza, Mira.

García Marcos, F. J. (1999): Fundamentos críticos de sociolingüistica. Almería, Univ. de Almería. Gémar, J. C. (1978): Bibliographie sélective du traducteur, droit et justice. Montréal, Linguatech.

Giho, J.; J. Bichot y M. Martin. (1998²): Dictionnaire de droit, économie et gestion. París, L'Hermès. Gobernado, R. (1978): Ideología, lenguaje y derecho. Madrid, CUPSA.

Goofman, E. (1981): Forms of Talk. Oxford, Blackwell.

González, de Pérez y, M. S. y M. L. Rodríguez de Montes. (2000): Lenguas indigenas de Colombia. Una visión descriptiva. Santafé de Bogotá, Instituto Caro y Cuervo.

Grewendorf, G. (1985): "Vertrauen in Misstrauen: linguistische Analyse zur Argumentation des Bundesverfassunsgerichts anlässlich des Urteils zur vorzeitigen Auflösung des 9 Deutschen Bundestagen", Rhetorik, 4, págs. 101-115.

Grewendorf, G. (1991): "Umpraktische Sprachethik", Ethik und Sozialwissenschaft, 2.

Grewendorf, G. (ed.) (1992): Rechtskultur als Sprachkultur: zur forensischen Funktion der Sprachanalyse. Frankfurt am Main, Suhrkamp.

Guillien, R. y J. Vincent. (1985): Lexique de termes juridiques. Paris, Dalloz.

Gumperz, J. (1982a): Discourse Strategies. Cambridge, Cambridge U. P.

Gumperz, J. (1982b): "Fact and interferente in courtroom testimony". En Gumperz (ed.): Language and Social Identity. Cambridge, Cambridge U. P.

Haehling von Lanzenauer, R. (1980): Der Eisenbahnattentäter Monsieur X. Heidelberg, Kriminalistik Verlag.

Halliday, M. A. K. (1978): El lenguaje como semiótica social. La interpretación social del lenguaje y el significado. México, F.C.E., 1982.

Hatim, B. (2001): Teaching and researching translation. Londres, Longman.

Hehn, W. (1992): "Sprache und und Erpressung". En Grewendorf, G. (ed.) págs. 194-206.

Heike, G. (1990): "Stimmenvergleichungsgutachten- Probleme und Methoden der forensischen Phonetik am Beispiel einer Fallstude". En Kniffka, H. (ed.) págs. 481-491.

Hengenbarth, R. y R. Scholz. (1979): "Konfliktlösung ohne Kommunikation. Die Organisation der Sprachlosigkeit in Zivilprozessen", Informationsbrief für Rectsoziologie, 15, págs. 88-118.

Henríquez, M. C. y M. N. de Paula. (1998): Prefijación, composición y parasintesis en el léxico de la jurisprudencia y la legislación. Vigo, Depto. de Filología Española. 
Hernández-Gil, A. (1987): "Saber jurídico y lenguaje". Obras Completas, tomo VI. Madrid, EspasaCalpe.

Hernández Terrés, J. M. (1994): "Particularidades lingüísticas del acto del juicio oral: la función dialógica del juez". En E. Serra et al. (eds). Panorama de l'investigació lingüística a l'Estat Espanyol. Valencia, Univ. de Valencia, págs. 42-48.

Herrero Muñoz-Cobo, B. (1994): "La interpretación en los juzgados". En V. R. Martín-Galtero (ed.), Encuentros Complutenses en torno a la traducción. Madrid, Univ. Complutense, págs. 687-692.

Hilgendorf, B. (1980): “Bibliographie". En S. Grosse y W. Mentrup (eds.): Bürger-Formulare-Behörde. Tubinga, G. Narr.

Hoffmann, L. (1980): “Zur Pragmatik von Erzählformen vor Gericht”. En K. Ehlich (ed.): Erzählen im Alltag. Frankfurt (Main), Suhrkamp, págs. 28-63.

Hoffmann, L. (1988): "Vom Ereignis zum Fall. Sprachliche Muster zur Darstellung und Überprüfung von Sachverhalten vor Gericht". En J. Schönert (ed.): Erzählte Kriminalität. Zur Typologie und Funktion von narrativen Darstellungen in Strafrechtspflege, Publizistik und Literatur. Tubinga, Niemeyer, págs. 64-96.

Hoffmann, L. (1992): "Wie vertändlich können die Gesetze sein". En Grewendorf, G. (ed.), págs. 122-154.

Hudson, J. (1980): La sociolingüística. Barcelona, Anagrama, 1981.

Iturralde Sesma, V. (1989): Lenguaje legal y lenguaje jurídico. Cuestiones relativas a la aplicación de la ley. Madrid, Tecnos.

Hymes, D. (1972): "Sociolinguistics: Current Trends and Prospects". En R. Shuy (ed.): Sociolinguistics. Current trends and prospects. Washington, Georgetown U. P., págs. 313-333.

Hymes, D. (1974): Foundations of Sociolinguistics: An Ethnographic approach. Filadelfia, Pennsylvania U. P.

Jodlbauer, R. y W. Wildgen. (1980): "Dialogische Strukturen bei richterlichen Anhörungen in der psychiatrischen Anstalt". En Kühlwein, W y A. Raasch, (eds.): Sprache und Verstehen, I, Tubinga, Narr, págs. $79-85$.

Jöns, D. (1982): "Der philologische Steckbrief. Über den Einsatz der Philologie bei der Täterermittlung". En AA. VV: Gesellschaft und Universität. Manheim, Univ. Manheim, págs. 273-287.

Kalin, R. (1982): "The social significance of speech in medical, legal and occupational settings". En Ryan, E. B. y R. Giles (eds.): Attitudes toward language: variation social and applied contexts. Londres, Arnold, págs. 148-163.

Kalverkämper, H. (1978): "Die problematik von Fachsprache und Gemeinsprache". Sprachwissenschaft, 3, págs. 406-444.

Kniffka, H. (1981) "Der Linguistit als Gutachter bei Gericht. Überlengungen und Materialien zu einer "Angewandten Soziolinguistik"'. En Peuser, G. y S. Winter (eds.): Angewandte Sprachwissenschaft. Grundfragen - Bereiche - Mhetoden. Bonn, Bouvier, págs. 584-634.

Kniffka, H. (1989): "Thesen zu Stand und Aufgaben "forensicher Linguistik"”. En Bundeskriminalamt (BKA), Wiesbaden, págs. 205-236.

Kniffka, H. (1990a): Texte zu Theorie und Praxis forensischer Linguistik. Tubinga, Niemeyer.

Kniffka, H. (1990b): "Zur Theorie und Methodologie forensicher Linguistik". En L. Michel (ed.): Mannheimer Hefte für Schriftvergleichung, Juni 1990.

Kniffka, H. (1990c): "Einführung: 'Forensiche Linguistik"”. En H. Kniffka (ed.), págs. 1-56.

Kniffka, H. (1992) "Sprachwissenschaftliche Hilfe bei Täterermittlung". En Grewendorf, G. (ed.), págs. 157-193.

Labov, W. (1972): Modelos sociolingüisticos. Madrid, Cátedra, 1983.

Leodolter, R. (1975): Das Sprachverhalten von Angeklagten bei Gericht. Ansätze zu einer soziolinguistischen Theorie der Verbalisierung. Kronberg, Scriptor.

Levi, J. (1982): Linguistics, Language and Law. A Topical Bibliographie. Bloomington, Indiana Univ. Press. 
Lipold, G. (1992): "Am Telephon: der Täter, Möglichkeiten der linguistischen Sprecheridentifizierung".

En Grewendorf, G. (ed.), págs. 207-229.

Luzzati, C. (1990): La vaghezza delle norme: un'analise del linguaggio giuridico. Milán, Giuffrè.

Marín, T. (1998): "La traducción en organismos internacionales". En Félix Fernández, L. y E. Ortega Arjonilla (eds.), págs. 909-913.

Martín del Burgo, A. (2000): El Lenguaje del Derecho. Barcelona, Bosch.

Martín Martín, J. (1991): Normas de uso del lenguaje juridico. Granada, Comares.

Martín Rojo, L. y R. Whittaker (eds.) (1998): Poder-Decir o el poder de los discursos. Madrid, Arrecife.

Martín Rojo, L., Pardo, L. y R. Whittaker. (1998): "El análisis crítico del discurso: una mirada indisciplinada". En Martín Rojo, L. y R. Whittaker (eds.), págs. 9-35.

Mateo, M. V. (1998): Disponibilidad léxica en el COU almeriense. Estudio de estratificación social. Almería, Universidad de Almería

Mayoral, R. (1999): "Las fidelidades del traductor jurado: batalla indecisa" en M. Feria (ed.). Traducir para la justicia. Granada, Comares.

Menne, H. (1975): "Sprachbarrieren und Rationalisierung in Zivilprozess". Zeitschrifts für Zivilprozess, 88, págs. 263-285.

Michel, L. (1982): Gerichtliche Schriftvergleichung. Berlín, De Gruyter.

Michel, L. (1990): "Forensiche Schriftuntersuchung -gestern, heute und morgen", Manheimer hefte für Schriftvergleichung, 15, págs. 137-150.

Miguel, E. 2000. "El texto jurídico-administrativo: análisis de una Orden Ministerial", Revista de Lengua y Literatura Española, 2, págs. 6-31.

Milroy, J. (1984): Applied Sociolinguistics. Methodology and the Identification of Speakers voices in Legal Proceedings. Londres, Academic Press.

Monzó, E. (2002): La professió de traductor juridic i jurat: descripció siológica del profesional $i$ analisi discursiva del transgènere. Tesis Doctoral inédita, Universidad Jaime I.

Neuman, U. (1992): "Juristische Fachsprache und Umgansprache". En Grewendorf, G. (ed.), págs. 110-121.

Nofsinger, R. E. (1983): "Tactical coherence in Courtroom Conversation". En Craig, R. T. y K. Tracy (eds.). Conversational Coherence. Beverly Hills, Sage, págs. 243-258.

Northdurf, W. (1987): "Die Ordnung des Konflikts. Gesprächanalyse der Konfliktbehandlungin einer Güteverhandlung vpon dem Schiedsman". En Röhl, K. F. (ed.): Das Güterverfahrenvor des Schiedsman. Colonia, Heymans, págs. 566-609.

O'Barr, W. M. (1976): "The study of language and politics". En W. M. O'Barr y J. F. O'Barr (eds.), págs. 1-27.

O'Barr, W. M. (1982): Linguistic evidence: language, powerand stategy in the courtroom. Nueva York, Academic Press.

O'Barr, W. M. y J. F. O'Barr (eds.) (1976): Language and politics. Contributions to the sociology of language, 10. La Haya, Mouton.

Oeverman, U. (1972): Sprache und soziale Herkunft. Francfort, Suhrkamp.

Oksaar, E. (1967): "Sprache als Problem und Werkzeug des Juristen", Archiv für Rechts- und Sozialphilosophie, 53, págs. 91-132.

Oksaar, E. (1979a): "Verständnisschwierigkeiten als sprachliches Problem". En R. Wassermann (ed.): Menschen vor Gericht. Neuwied - Darmstadt, Luchterhand, págs. 83-116.

Oksaar, E. (1979b): "Sprachliche Mittel in der Kommunikation zwischen Fachleuten und Laien im Bereich des Rechtswesens". En W. Mentrup (ed.): Fachsprachen und Gemeinssprache. Jahrbuch des IDS 1978. Düsseldorf, Schwann, págs. 100-113.

Olivecroma, K. (1962): Lenguaje jurídico y realidad. México, Fontamara, 1995.

Ortega Arjonilla, E. et al. (1996): "Peculiaridades del lenguaje jurídico desde una perspectiva lingüistica". En San Ginés, P. y E. Ortega Arjonilla (eds.), págs. 25-40. 
Pardo, M. L. (1992): Derecho y lingüistica. Cómo se juzga con palabras. Buenos Aires, Nueva Visión. Philips, S. V. (1984): "Contextual Variation in Courtroom Language Use: Noum Phrases Refering to Crimes". En H. Coleman (ed.), págs. 29-50.

Philips, S. V. (1985): "Strategies of clarification in judges use of language: fron the written to the spoken", Discourse processes, 8, págs. 421-436.

Philips, S. V. (1986): "Some Functions of Spatial Positioning and Aligment in the Organization of Courtroom Discourse". En Fisher, S.y A. D. Todd (eds.): Discourse and Institutional Authority: Medecine, Education and Law. Nordwoord, Abblex, págs. 223-233.

Podlech, A. (1975): "Rechtslinguistics". En Grimm, D. (ed.): Rechtswissenschaft und Nachbarwissenschaften. Munich, Beck, págs. 105-116.

Pousada, A. (1983): "Interpreting for Language Minorities in the Courts". En Craig, R. T. y K. Tracy (eds.), Conversational Coherence. Form, Structure and Strategy. Beverly Hills, Sage, págs. 186-208.

Prieto de Pedro, J. (1991): Lenguas, lenguaje y Derecho. Madrid, Civitas.

Rehbein, J. (1972): "Entschuldigungen und Rechtfertigungen". En D. Wunderlich (ed.): Linguistische Pragmatik. Frankfurt (Main), Athenäum, págs. 288-317.

Reiher, R. (ed.) (1995): Sprache im Konflikt. Zur Rolle der Sprache in sozialen, politischen und militärischen Auseinandersetzungen. Berlín/Nueva York, De Gruyter.

Reitemeier, U. (1985): Juristische Kommunikation: eine kommentierte Bibliographie. Tubinga, G. Narr. Ribó Durán, L.(1987): Diccionario de Derecho. Barcelona, Bosch.

Rodríguez-Aguilera, C. (1969): El lenguaje juridico. Barcelona, Bosch.

Rodríguez Zulaica, A. (1995): Diccionario de términos juridicos. Madrid, Acento.

Ruiz Vadillo, C. (1991): Introducción al Derecho. Logroño, Ochoa.

San Ginés Aguilar, P. y E. Ortega Arjonilla (eds.) (1996): Introducción a la traducción juridica y jurada. Granada, Comares.

Sacks, H., E. Schegloff y G. Jefferson. (1974): "A symplest systematics for the organization of turntaking for conversation", Language, 50, págs. 696-735.

Safford, J. B. (1977): "No comprendo: the non-English speaking Defendantg and the criminal process", Journal of Criminal Law and Criminology, 68/1, págs. 15-30.

Sánchez Montero, $\mathrm{M}^{\mathrm{a}}$ C. (1996): Aproximación al lenguaje jurídico. Padua, Università degli Studi di Trieste.

Sarcevic, S. (1997): New Approach to Legal Translation. La Haya, Kluwer Law Internacional.

Saville-Troike, M (1982): The ethnography of communication. Oxford, Blackwell.

Schröder, P. (1987): "Sprachliches Funktionieren und Interaktive Funktion von Stereotypen in einer Güterverhandlung vor dem Schiedsmann". En Rhöl, K. F. (ed.): Das Güterverfahren vor dem Schiedsmann. Colonia, Heymanns, págs. 667-722.

Schütze, F. (1978): "trategische Interaktion im Verwaltungsgericht - eine soziolinguistische Analyse zum Kommunikationsverlauf im Verfahren zur Anerkennung als Wehrdientsverweigerer". En W. Hassemer, W. Hoffmann-Riem y M. Weiss (eds.): Interaktion vor Gericht. Baden-Baden, Nomos, págs. 19-100.

Seibert, Th. M. (1977): “Argumentationsbeispiele aus dem Rechtsbereicht". En M. Schecker (ed.): Theorie der Argumentation. Tubinga, Narr, 313-353.

Serrano, S. (1980): Signes, llengua i cultura. Barcelona, Edicions 62.

Skutnabb-Kaugas, T. y R. Philipson (eds.) (1994): Linguistic Human Rights. Berlín/Nueva York, De Gruyter.

Slembeck, E. (1981): “Individuelle Identifikation und soziale Bewertung von Gesprächspartnern durch Sprechausdrucksmerkmale", Germanistische Linguistik, 5-4, págs. 199-222.

Solan, L. M. (1993): The Language of Judges. Chicago, Chicago Series in Law and Society.

Terral, F. (2002): La traduction juridique dans un contexte de pluralisme linguistique. Le cas du Règlement (CE) 40/94 sur la marque communautaire. Tesis Doctoral inédita, Universitat Autònoma de Barcelona. 
Tosi, O. (1979): Voice Identification: Theory and Legal Application. Baltimore, Baltimore Univ. Press.

Van Scriver, E. M. (1985): "The language of the law and its impact in society: a sociolinguistics analysis of a jury charge", L.A.U.T., 125. Trier, Univ. Trier.

Varaux, J.-M. (1989): “Lieu, moment et alngage de la justice pénale. Esquisse d'une phénoménologie de l'audience“. Gaz, Pal. II Chron., 19-21 nov.

Way, C. (2003): La traducción como acción social. El caso de los documentos académicos (españolinglés). Tesis Doctoral inédita, Universidad de Granada.

Véglia, A. (2000): "Introducción a la traducción jurídica". En F. Navarro (ed.): Introducción a la teoría y práctica de la traducción, ámbito hispano-francés. Alicante, Editorial Club Univesitario.

Wildgen, W. (1983): "Dialogdynamik: erste Amsätze zu einer Erfassung der Dynamik verbaler Interaktionen am Beispiel rechterlicher Anhörung”, Papiere zur Linguistik, 2, págs. 3-21.

Wunderlich, D. (1971): "Zum Status der Soziolinguistik". En Klein, W. y D. Wunderlich (eds.): Aspekte der Soziolinguistik. Frankfurt, Atenäum, págs. 297-321. 